\title{
De los mapas de zonas afectadas a las cartografías de riesgo de inundación en España ${ }^{1}$
}

\author{
Jorge Olcina Cantos \\ Instituto Interuniversitario de Geografía \\ Universidad de Alicante \\ jorge.olcina@ua.es
}

Recibido: 16 de Agosto de 2011

Enviado a evaluar: 10 de Febrero de 2012

Aceptado: 23 de Marzo de 2012

\begin{abstract}
"Cuando se produce una inundación desastrosa, resulta frecuente que se diga desde diversas instancias potencialmente implicadas que fue imprevisible. Si un suceso es imprevisible, no hay responsabilidades. Si es imprevisible, nada pudo hacerse para prevenirlo, ninguna lección puede sacarse para evitarlo en el futuro. Un panorama desolador para la ciudadanía"
\end{abstract}

Francisco J. Ayala-CARCEDo, 2002

\section{RESUMEN}

Las inundaciones son un fenómeno propio de los rasgos geográficos de nuestro país. En todo momento histórico se han desarrollado crecidas fluviales y desbordamientos que han ocasionado daños económicos y pérdida de vidas humanas. Los documentos escritos (informes, memoriales) han dejado testimonio de estos episodios extremos y desde la Edad Moderna se acompañarían de mapas de zonas afectadas. Sólo desde los años ochenta del pasado siglo estos cartogramas dibujarán mapas de riesgo en relación con la evolución conceptual y de método del análisis de riesgo, la mejora de los sistemas de representación cartográfica y la aparición de normativas que obligarán a su realización como herramienta básica para la planificación territorial.

Palabras clave: Inundaciones, riesgo, mapas de zonas afectadas, cartografía de riesgo.

\section{From maps of affected areas to flood risk maps in Spain}

\begin{abstract}
Floods are an own phenomenon of the geographical characteristics of our country. In every historical moment have developed river floods that have caused economic damage and life loss. Written documents (reports, memorials) have left evidence of these extreme events, and since the Modern Age would
\end{abstract}

\footnotetext{
${ }^{1}$ Este trabajo reúne aportaciones del autor realizadas en el marco del proyecto de investigación "Riesgo y desastre natural en la España del siglo XVIII. episodios meteorológicos extremos y sus efectos a través de la documentación oficial, la religiosidad popular y la reflexión científica" (HAR200911928).
} 
be annexed maps of affected areas. Only since the eighties of last century these cartograms draw risk maps in relation to the conceptual and method of risk analysis advances, in relation to the improvement of mapping system and the development of legal regulations that force its realization as a basic tool for spatial planning.

Key words: Floods, risk, maps of affected areas, risk maps.

\section{Des de les cartes des zones affectées aux les cartes de risque d'inondationen Espagne}

\section{RÉSUMÉ}

Les inondations sont un phénomène naturel des caractéristiques géographiques de notre pays. Tout au long de l'histoire des inondations ont été élaborés et ont causé d'énormes dégâts économiques et la perte de la vie. Les documents écrits (rapports, mémoirels) ont laissé des preuves de ces phénomènes naturels extrêmes et de l'âge moderne sont accompagnés par des cartes des zones affectées. Depuis les années quatre-vingt du XXe siècle commencent à dessiner des cartes de risques en ce qui concerne le développement conceptuel et méthodologique de l'analyse des risques, les progrès dans les systèmes de cartographie et l'élaboration de règlements qui déterminent sa performance comme un outil de base pour l'amenagement du territoire.

Mots-clés: Inoundations, risque, cartes de zones affectées, cartographie des risques.

\section{CONCEPTOS BÁSICOS: DEL DESASTRE AL RIESGO Y SUS PRODUCTOS CARTOGRÁFICOS}

El riesgo es una condición condigna al ser humano desde el inicio de la historia de la Humanidad. El desconocimiento del funcionamiento de la Naturaleza y el temor ante sus fenómenos extremos en los primeros momentos o la pérdida del respeto hacia lo ambiental en tiempos más recientes, han convertido la espera de la catástrofe en un elemento común de la vida cotidiana. La probabilidad de que acontezca un peligro natural se ha asumido como un aspecto más del devenir de las sociedades en todo momento histórico. El ser humano convive con el riesgo sobre la superficie terrestre. Y el fenómeno no es algo contemporáneo. Tampoco sus conceptos.

En las últimas décadas se ha conceptualizado el riesgo, ha adquirido categoría de disciplina científica, pero la reflexión sobre los peligros naturales y sus efectos ha existido siempre. Y han ido surgiendo vocablos que aluden al comportamiento extremo de la naturaleza y a las consecuencias para las sociedades. Uno de los primeros términos manejados en las crónicas de la Antigüedad fue el vocablo latino calamidad, de origen griego (de $\kappa \alpha \lambda \alpha \mu \eta$, tallo, caña, paja, rastrojo), con el que se hacía mención a la "tempestad que destruye las cosechas, las cañas del trigo o la cebada", evidenciando el carácter agrícola de las civilizaciones antiguas que se mantuvo hasta el siglo

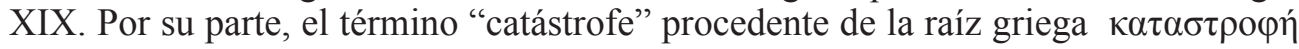
(del verbo $\kappa \alpha \tau \alpha \sigma \tau \rho \varepsilon ́ \varphi \varepsilon \imath v)$ significa abatir, destruir y con él se aluddía al suceso infausto que llega a alterar gravemente el orden regular de las cosas. 
Algo más tardía fue la aparición del término desastre o "desgracia grande, suceso infeliz y lamentable", procedente del provenzal y compuesto del prefijo latino "des -separación-" y el vocablo "astro" (estrella). Con esta palabra se designaba la observación de un acontecimiento estelar excepcional por el que una estrella o cuerpo fulgurante observado en el cielo se desintegraba en mil direcciones hasta desaparecer. Este desorden estelar se interpretaba como augurio de catástrofes y desgracias.

Por su parte, el término "riesgo" se habría conceptuado definitivamente en la Edad Moderna, sin que falten antecedentes medievales de su significado. El Diccionario Etimológico de Corominas señala que el vocablo riesgo tiene la misma etimología que "risco" (peñasco alto) y se vinculaba al peligro que sufrían los barcos al navegar por mares de poco calado. Por tanto, su origen etimológico vendría del verbo latino "reseco" (rasgar, dividir). Hay autores que lo hacen descender del término griego $\dot{\rho} i \zeta \alpha$ (ríza, "escollo"), a través de una forma derivada ṕílikov (risikon).

El Diccionario de la Real Academia, hasta la edición 22a, hacía derivar el término riesgo del vocablo antiguo "resgar" (cortar), procedente del señalado verbo latino

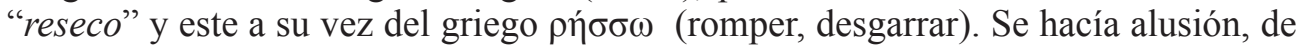
este modo, a la idea de ruptura de la normalidad que supone la asunción de un riesgo. La edición $22^{\mathrm{a}}$ del Diccionario introdujo un cambio en la etimología de este concepto al indicar que "riesgo" procede del italiano risico o rischio, y éste del árabe clásico. rizq, que significa "lo que depara la providencia".

De un modo u otro, subyace la idea de que el riesgo supone el desarrollo de una nueva situación y, generalmente, una ruptura con lo anterior que abre un nuevo escenario de incertidumbre. Nocenzi (2002) relaciona el concepto riesgo con la innata propensión que desde la Antigüedad, ha tenido el ser humano a indagar en lo desconocido, a pesar de las consecuencias negativas que ello podía suponer. Sennett (1998) ha señalado que la palabra "riesgo" (risicare) habría aparecido por ver primera en la obra "Liber Abaci" (1202) de Leonardo Fibonacci "El Pisano" en la que este autor indaga en la posibilidad de calcular, con los números árabes, cantidades imposibles de hallar en la numeración romana, aspecto que sería demostrado algunas centurias más tarde por los matemáticos Paccioli, Pascal, Jacob y Bernoulli.

Anthony Giddens (2003) encuentra el origen del concepto riesgo en la Edad Moderna en el empleo que de esta palabra realizaron los exploradores occidentales en sus viajes por el mundo. La expresión habría llegado al inglés a través del español o del portugués, donde se usaba para referirse a la navegación marítima por aguas desconocidas. De manera que, como señala el sociólogo inglés, el concepto estuvo en sus orígenes vinculado al espacio geográfico. De ahí se trasladaría al mundo financiero para indicar el cálculo de las consecuencias probables de las decisiones inversoras para prestamistas y prestatarios. En este sentido, la primera edición de la Enciclopaedia Britannica (1771) vincula, precisamente, el término "risk" con la probabilidad en el juego. En las ediciones modernas de dicha Enciclopedia se relaciona el término con la cuota que se establece para cubrir los riesgos en una inversión o préstamo (vid. figura 1). 
Figura 1. Concepto de riesgo ("risk") en la 1ª edición de la Enciclopaedia Britannica (1771)

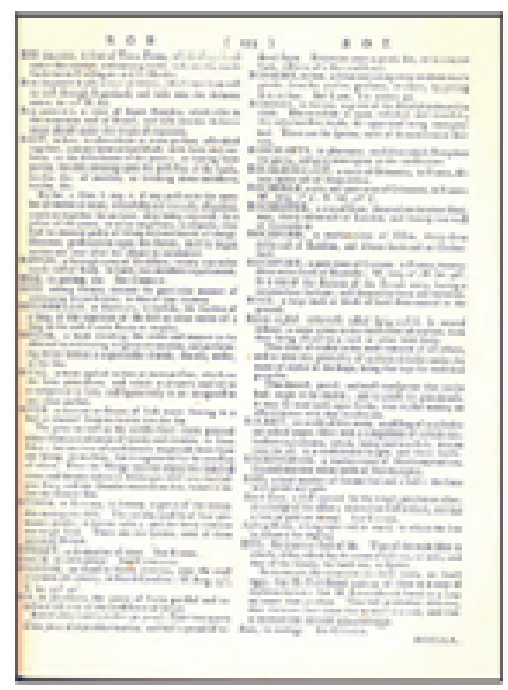

\section{RISK, in gaming, to. See Chance,}

Fuente: Enciclopaedia Britannica. Vol. III. Edición facsimil, 1771. (Printed for A. Bell and C. MacFarquhar; and sold by C. MacFarquhar at his printing-office, Nicolsonstreet)

En la actualidad, el término riesgo se emplea para referirse a una amplia gana de situaciones de inseguridad y encuentra una estrecha relación con el "principio de incertidumbre” que demostrara en 1927 el físico alemán Werner Heisenberg y que resultó fundamental para el desarrollo de la mecánica cuántica. Dicho principio crearía una revolución en la física moderna puesto que revelaba una característica distintiva de la mecánica cuántica que no existía en la mecánica newtoniana. El principio de incertidumbre señala que ciertos pares de variables físicas, como la posición y el momento (masa por velocidad) de una partícula, no pueden calcularse simultáneamente con la precisión que se quiera. Así, si repetimos el cálculo de la posición y el momento de una partícula cuántica determinada (por ejemplo, un electrón), nos encontramos con que dichos cálculos fluctúan en torno a valores medios. Estas fluctuaciones reflejan, pues, nuestra incertidumbre en la determinación de la posición y el momento. Según el principio de incertidumbre, el producto de esas incertidumbres en los cálculos no puede reducirse a cero. El principio de incertidumbre postula que en la mecánica cuántica es imposible conocer exactamente, en un instante dado, los valores de dos variables canónicas conjugadas (posición-impulso, energía-tiempo,..., etc.) de forma que una medición precisa de una de ellas implica una total indeterminación en el valor de la otra. La incertidumbre es muy pequeña, y resulta despreciable en mecánica clásica. En cambio, en la mecánica cuántica las predicciones precisas de la mecánica clásica se ven sustituidas por cálculos de probabilidades. La matemática del riesgo se basa, en muchos aspectos, en el cálculo de probabilidades y, aunque ello no tiene 
coincidencia exacta con la realidad geográfica, ha sido asumido por la legislación para definir situaciones y grados de riesgo (períodos de retorno).

Aunque en todo momento histórico ha existido una preocupación por encontrar las causas que originaban catástrofes naturales, el estudio científico del riesgo natural comenzó en la geografía a mediados del siglo XX y es en esta disciplina donde ha adquirido su sentido pleno. Porque el riesgo aúna los tres componentes esenciales del funcionamiento de las sociedades sobre la Tierra: el ser humano, la Naturaleza y el espacio geográfico -el territorio- donde se producen las relaciones entre ambos. La "geografía de los riesgos" es, además, un punto de encuentro de los diferentes enfoques geográficos. La investigación sobre riesgos naturales precisa conocimientos de la geografía física y de la dinámica de las sociedades que se localizan en un territorio, en un ámbito regional. Y en este carácter de disciplina de análisis, riguroso y profundo y, a un tiempo, de síntesis, está su gran virtud, su tarjeta de presentación ante la sociedad.

Los trabajos de los norteamericanos White, Burton y Kates fueron los primeros que manejan el concepto de "riesgo" en sentido moderno y otorgan un enfoque global (importancia del factor humano en la consideración del grado de riesgo) al tratamiento de los eventos excepcionales de la naturaleza (geofísicos y atmosféricos). En un estudio del año 1964 Burton y Kates, en lo que se tiene como el paradigma dominante en la investigación geográfica sobre los riesgos naturales (Sauri, 1988), definirán el riesgo natural como el conjunto de elementos del medio físico y biológico nocivos para el hombre y causados por fuerzas ajenas a él. Fruto de toda esta labor, en 1969 la UNESCO y la Comisión sobre el Hombre y su Medio Ambiente de la Unión Geográfica Internacional deciden iniciar, como una de sus dos principales líneas de acción para el trienio siguiente, un programa de colaboración internacional para el estudio de los problemas planteados por los riesgos y peligros del medio ambiente. Por esos años, otro hito destacado fue el establecimiento, en 1972, de los fundamentos de la llamada "teoría de catástrofes" por parte de René Thom y Cristopher Zeeman que ha tenido aplicación posterior al estudio de la peligrosidad natural y sus efectos sociales en espacios regionales (Casetti, 1981, Martín Vide, 1993) .

Y junto a la geografía han venido a coincidir una amplia relación de disciplinas en sus aproximaciones al riesgo (sociología, geología, psicología, ingenierías, medicina, periodismo, ciencias ambientales, física, química, entre otras). De hecho, las investigaciones de Burton, Kates y White sobre la percepción del riesgo derivado de la ocupación de lechos de inundación en diversos territorios de Norteamérica contaron, en ocasiones, con la colaboración de psicólogos que tenían como misión evaluar los rasgos de la personalidad que afectan a las decisiones relativas a los riesgos. Se trata, por tanto, de una rama del conocimiento donde convergen ciencias naturales, sociales, históricas, económicas, disciplinas técnicas, en sus aspectos básico y aplicado, puesto que el estudio de un acontecimiento excepcional implica el análisis de los diferentes sistemas (físicos y humanos) que se dan en un territorio en cada momento histórico. Y la propia Administración, a través de sus cuadros técnicos, ha incorporado la planificación del riesgo y la gestión de las emergencias, entre sus tareas como respuesta a las demandas de la sociedad. 
Los últimos decenios han sido pródigos en la manifestación de episodios naturales de rango extraordinario de consecuencias funestas para la población mundial. Se ha creado la impresión de una mayor ocurrencia -todavía por comprobar- de eventos excepcionales, cuando lo realmente ocurrido es el incremento de la exposición de las poblaciones del mundo a los peligros naturales. Los umbrales de tolerancia ante los riesgos de la naturaleza han disminuido por el propio crecimiento de la población mundial y la ocupación intensiva del territorio. Se invaden espacios con riesgo bajo la premisa del desarrollo colectivo permitiendo que los grupos sociales tornen vulnerables a la más mínima manifestación de las fuerzas de la naturaleza.

En este nuevo contexto hay un elemento, eminentemente geográfico, que ha cobrado destacada importancia en los últimos años en los análisis del riesgo natural: el mapa. Se trata de una herramienta esencial en los estudios de riesgo natural que ha experimentado un avance muy notable en los últimos años en relación con la aplicación de las modernas tecnologías cartográficas. La posibilidad de relacionar, de forma inmediata, usos del suelo con la peligrosidad natural, a fin de establecer grados de exposición y vulnerabilidad ante un episodio de rango extraordinario, ha impulsado la elaboración de cartografías de riesgo; con la ventaja añadida de su posible actualización continua. Como señaló Hartshorne "si un problema no puede estudiarse fundamentalmente mediante mapas, entonces será cuestionable que pertenezca al campo de la Geografía", y este aspecto resulta esencial cuando se aborda un análisis de riesgo. En efecto, la elaboración de un mapa de riesgo donde se localizan territorios con riesgo ante un peligro natural de rango extraordinario y la determinación del nivel de riesgo es básica para la gestión de un esoacio geográfico.

Tal y como se ha señalado sobre la aparición de conceptos manejados en los estudios de riesgo (vid. supra), también la cartografía relacionada con la peligrosidad natural y sus efectos ha experimentado evolución y cambios relacionados con el propio desarrollo de las técnicas de representación y con los criterios a la hora de representar los territorios con riesgo. Los episodios extremos de inundación son los primeros que merecieron la elaboración de mapas; y los mapas de inundaciones son, realmente, los que han tenido una evolución en sus métodos y técnicas cartográficas más cuajada.

Las primeras cartografías relacionadas con la representación de espacios afectados por inundación en España fueron cartogramas con referencias "indirectas", esto es, mapas de actuaciones en espacios fluviales regularmente afectados por estos episodios, con objeto de prevenir futuras inundaciones. De ahí, se pasó a los mapas de zonas afectadas, dibujados tras un episodio importante; son los llamados "mapas de calamidad", donde se localizaban zonas afectadas. Y, finalmente, se han desarrollado los mapas de riesgo, que señalan las áreas geográficas expuestas a un peligro en función de la dinámica natural (evento extremo) y de la ocupación humana de un territorio (vid. Tabla 1). A partir de ello se establecen niveles o grados de riesgo. En la actualidad, la preparación de estos mapas ha adquirido rango normativo y se ha convertido, afortunadamente, en requisito imprescindible en los procesos de transformación de usos. 
Tabla 1. Evolución de las cartografías de inundación y consideración socio-política del fenómeno

\begin{tabular}{|c|c|c|}
\hline PERIODO & $\begin{array}{l}\text { CONSIDERACIÓN } \\
\text { SOCIALY } \\
\text { ADMINISTRATIVA } \\
\text { DE LAS } \\
\text { INUNDACIONES }\end{array}$ & PRODUCTO CARTOGRÁFICO \\
\hline $\begin{array}{c}\text { EDAD MODERNA } \\
\text { HASTA FNALES } \\
\text { s. XX }\end{array}$ & $\begin{array}{l}\text { FENÓMENO EXTREMO } \\
\text { (inumdaciones) } \\
\text { COMO ALOO } \\
\text { DEVITABLE } \\
\text { ("EXCEPCIONAL", } \\
\text { "EXTRAORDNARIO") } \\
\text { MAPA } \rightarrow \text { Doctumento } \\
\text { informativo que iluntra } \\
\text { sobre ireas afectadas }\end{array}$ & 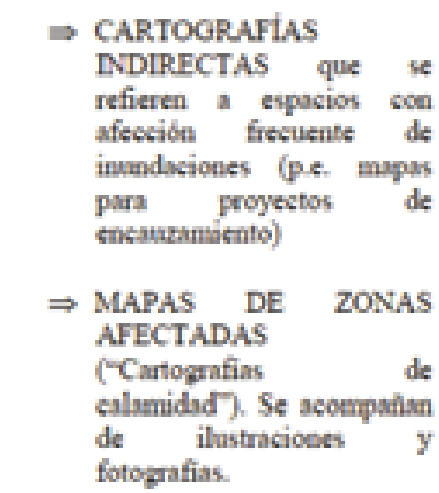 \\
\hline $\begin{array}{l}\text { FNALES } \\
\text { s. } \mathrm{xX} \\
\mathrm{y} \\
\text { COMTENZOS } \\
\text { s. } \mathrm{XXI}\end{array}$ & $\begin{array}{l}\text { FENÓMENO EXTREMO } \\
\text { (inumdasiones) } \\
\text { COMO ALGO } \\
\text { PREVISIBLE } \\
\text { MAPA } \rightarrow \text { Documento } \\
\text { operativo para la } \\
\text { planificación territorial }\end{array}$ & $\begin{array}{l}\Rightarrow \text { MAPAS DE RIESGO DE } \\
\text { DUNDACIÓN. } \\
\text { Establesimiento de niveles } \\
\text { de riesgo. }\end{array}$ \\
\hline
\end{tabular}

Fuente: Elaboración propia

Como dato general, no ha habido hasta los años ochenta del pasado siglo un interés explícito, ni obligación legal, de incorporar cartografía de zonas afectadas por inundaciones en informes de daños. Su inclusión ha dependido de la voluntad y de la capacitación profesional del redactor de los mismos. Más frecuente ha sido la incorporación a informes de daños de dibujos y fotografías que muestran los efectos de las crecidas fluviales. Las cartografías de zonas afectadas por inundaciones en España han sido elaboradas, en sus inicios, por ingenieros (de caminos o montes) y desde la segunda mitad del siglo XX por geógrafos, en relación con la consolidación de la enseñanza universitaria de esta disciplina en nuestro país. 


\section{EVIDENCIAS CARTOGRÁFICAS "INDIRECTAS": PLANOS DE ENCAUZAMIENTOS, OBRAS DE DEFENSA DE AVENIDAS...}

Una primera etapa en la evolución de las cartografías de inundación en España, que se desarrolla a lo largo de la Edad Moderna, incluye aquellas referencias cartográficas que representan espacios fluviales bien por tratarse de áreas objeto de actuación (proyectos de encauzamiento o desviación de cauces) al haber originado problemas en núcleos de población, o bien por tratarse de espacios, en tramos bajos de aparatos fluviales, generalmente con avenamiento precario, sobre los que se ha implantado actividad agraria (regadíos) y asentamientos que resultan afectados por las crecidas fluviales. No son realmente mapas de zonas afectadas sino cartografías "indirectas" de áreas-problema ante inundaciones. Eso sí, constituyen las referencias cartográficas más antiguas de que hay referencias para el análisis de la evolución de los mapas de inundaciones en España.

En el presente análisis se ha fijado el final de este primer período de cartografías indirectas de inundación en nuestro país en los años finales del s. XVIII, puesto que a partir de entonces comenzará la elaboración de mapas de zonas afectadas por inundación de forma regular, que acompañaran informes y memoriales redactados tras un episodio importante de avenida fluvial. Ello no significa que a finales del s. XVIII finalicen los proyectos de actuación en cauces problemáticos con ocasión de crecidas que, por el contrario serán abundantes en los siglos XIX y XX. Deben recordarse las obras de encauzamiento y desviación de cursos fluviales de gran calado con objeto de defender a las poblaciones de las consecuencias de las inundaciones que se llevan a cabo en estos dos siglos. Es el caso, entre otras, de las actuaciones en el Guadalquivir (Sevilla 1929, 1950; Córdoba 1802, años sesenta s. XX), Turia (1957), Segura (1987); incluso a comienzos del siglo XXI, queda pendiente la realización de obras de remodelación del tramo bajo del río Júcar, incluidas en el Plan de Defensa de Avenidas de este curso mediterráneo y cuya documentación incluye cartografía de las actuaciones a llevar a cabo. Igualmente se encuentran proyectos de actuación en cauces anteriores al siglo XVI, como los analizados para la ciudad de Murcia medieval con descripción detallada de áreas de afección frecuente ante las inundaciones del Segura en el núcleo urbano (Martínez Carrillo, 2004). La cartografía que acompaña todos estos proyectos no es, sin embargo, objeto de análisis del presente estudio que se ha centrado en el análisis de las cartografías de inundaciones elaboradas en nuestro país.

Por lo que respecta a obras de acondicionamiento llevadas a cabo en cauces fluviales para evitar los efectos de desbordamientos en campos y, sobre todo, en áreas urbanas, es muy rica la relación de actuaciones que se desarrollan entre los siglos XVI y XVIII. Resulta interesante comentar algunos de ellos. La tabla adjunta (vid. tabla 2) recoge alguno de los proyectos de actuación en cauces fluviales destacados, llevados a cabo en España entre los siglos XVI y XVIII. 
Tabla 2. Obras de actuación en cauces fluviales destacadas llevadas a cabo en España (ss. XVI-XVIII)

\begin{tabular}{|c|c|}
\hline $\begin{array}{c}\text { AÑO- } \\
\text { PERÍODO }\end{array}$ & OBRA DE ACTUACIÓN EN CAUCE FLUVIAL \\
\hline 1555 & $\begin{array}{l}\text { Construcción de la Mina de Daroca para evitar inundaciones de la } \\
\text { rambla Fondonera. }\end{array}$ \\
\hline 1566 & $\begin{array}{l}\text { Obras de encauzamiento en la rambla de las Hoyuelas (Almansa). } \\
\text { Proyectos posteriores por inundaciones de mayo de } 1570 \text { y agosto de } \\
1580 \text {. Entre } 1580 \text { y } 1584 \text { se construye un nuevo cauce -"la zanja } \\
\text { Sangrentana". }\end{array}$ \\
\hline 1589 & $\begin{array}{l}\text { Creación de la institución "Fabrica nova del Riu" para llevar a cabo el } \\
\text { encauzamiento del Turia en Valencia tras la riada de octubre de } 1589 .\end{array}$ \\
\hline 1616 & Obras de encauzamiento en el río Bidasoa. \\
\hline 1759 & $\begin{array}{l}\text { Avenida rambla de Abanilla (problemas de desbordamiento en } \\
\text { tramo final (pleitos) }\end{array}$ \\
\hline $\begin{array}{l}\text { ss. XVII- } \\
\text { XVIII }\end{array}$ & Cortas en meandros del Segura para evitar desbordamiento \\
\hline s.XVIII & Proyectos de desviación tramo bajo del Ter \\
\hline s. XVIII & $\begin{array}{l}\text { Proyectos de acondicionamiento de cauces en Alcoi y Callosa de } \\
\text { Segura }\end{array}$ \\
\hline s. XVIIII & $\begin{array}{l}\text { Obras de acondicionamiento del Turia en Valencia (Junta de Murs y } \\
\text { Valls) }\end{array}$ \\
\hline 1736 & Proyecto de canalización del Baix Llobregat en Hospitales y San Boi. \\
\hline 1785 & $\begin{array}{l}\text { Proyecto de acondicionamiento del Segura en la ciudad de Murcia } \\
\text { (Manuel Serrano) }\end{array}$ \\
\hline
\end{tabular}

Fuente: Elaboración propia

La población de Daroca experimentó un crecimiento notable de su población residente en los siglos XII y XIII, lo que provocó una modificación importante de su caserío que de situarse en las faldas del cerro de San Jorge, pasó a ocupar el lecho de inundación de la rambla Fondonera. En barrio nuevo de la "Franquería", con su calle principal (calle Mayor) pasará a ocupar el cauce de esta barranquera, configurando así un espacio de riesgo ante las crecidas de dicho curso fluvial. Para evitar los efectos de las temibles avenidas de esta rambla se proyectó, en el siglo XVI un túnel por debajo del cerro de San Jorge para que condujese las aguas directamente al río Jiloca, evitando el paso por el centro de la villa. La obra se encargó al ingeniero francés Pierres Bedel, que inició los trabajos en el verano de 1555, culminando la excavación del túnel cinco años después. Lo curioso de la construcción de este túnel es que comenzó, a la vez, en las dos bocas del mismo y encontrándose los dos grupos de excavación en septiembre de 1560. En la entrada del túnel se construyó un muro de encauzamiento, llamado "la Barbacana", de trescientos metros de longitud. La obra 
de la Mina de Daroca fue una de las más costosas realizadas en Aragón pero pronto se convertiría en una obra muy celebrada y visitada por el propio monarca Felipe II. En 1742 el ingeniero Sebastián de Rodolphe levantaría un detallado plano de la Mina de Daroca (vid. Figura 2).

Figura 2. Plano de la Mina de Daroca levantado por Sebastián de Rodolphe (1742)

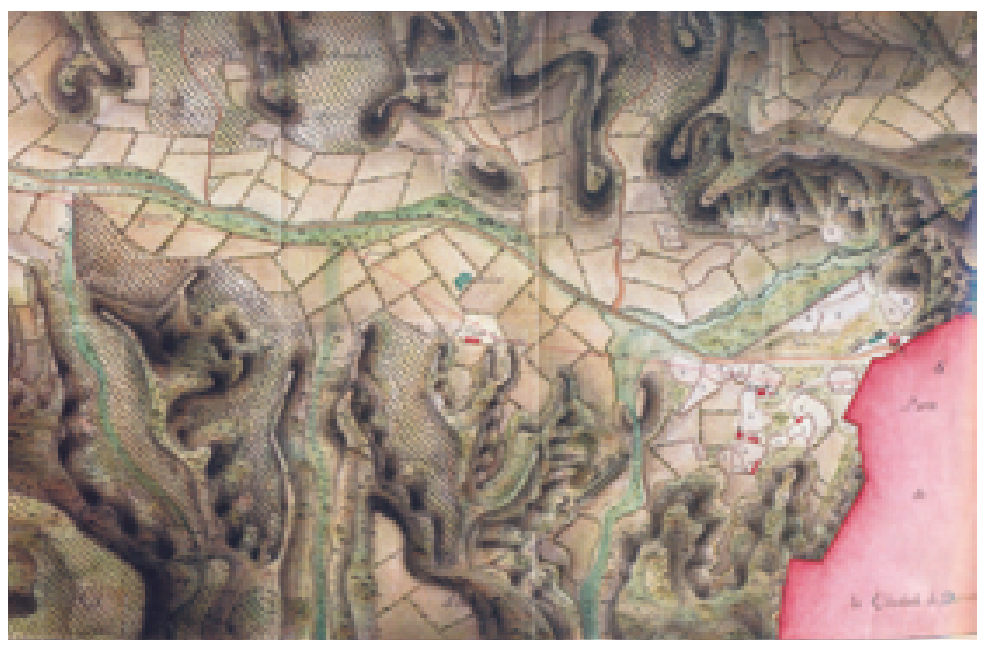

Fuente: Felipe II. Los ingenios y las máquinas, exposición, 1999

Destacados serían también los trabajos de encauzamiento de la rambla de las Hoyuelas en Almansa iniciadas en 1566 pero que tuvieron varias fases debido a la rotura provocada en las obras por la violenta avenida de mayo de 1570 y la destrucción en parte de la fábrica registrada en 1580; de manera que no sería hasta marzo de 1584 cuando finalizarían los trabajos del nuevo cauce realizado, que pondría fin a las inundaciones periódicas que se registraban en la ciudad.

Por la importancia del proyecto, el detalle del mismo y la incorporación de un rico material cartográfico merece destacarse, también, el Proyecto de canalización y ornato del río Segura a su paso por Murcia (1785) elaborado por D. Manuel Serrano "Arquitecto Director de Caminos" y con planos firmados por el propio autor y por D. José Moñino Redondo, Conde de Floridablanca. Se trata del proyecto más ambicioso y documentado de los que se habrían elaborado para solucionar el problema de las avenidas del río Segura en la ciudad de Murcia, a tenor por la documentación exhaustiva y planos elaborados, que se incluyen en el mismo. En efecto, amen de una descripción detallada de la problemática de inundaciones en la capital murciana, ocasionada por el propio río Segura y por los cauces afluentes -especialmente el Guadalentín- el proyecto se acompaña de dos planos que representan, sucesivamente, las zonas generalmente afectadas por las avenidas de estos cursos fluviales y las obras a realizar para evitar sus efectos (vid. figura 3). Es curioso destacar como en estos planos se recoge, por vez primera, en un cartograma oficial el término "riesgo" para 
hacer mención al peligro existente en los sectores urbanos próximos al río afectados por sus crecidas. Debe señalarse que a pesar de la implicación personal del Conde de Floridablanca en este proyecto, apenas se llevarían a cabo una serie de obras menores, que no supondrían apenas protección de la ciudad frente a las inundaciones ${ }^{2}$.

Figura 3. Descripción de zonas afectadas por las inundaciones en la ciudad de Murcia y detalle del mismo con aparición del término "riesgo" en un plano oficial
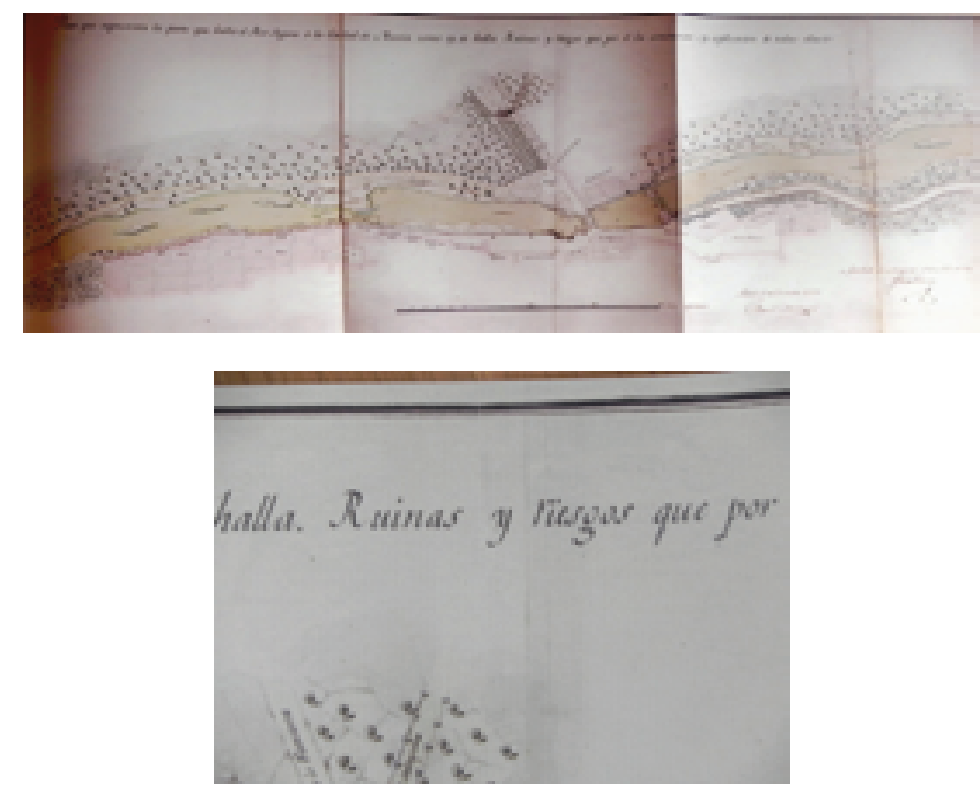

Fuente: Proyecto de canalización y ornato del río Segura a su paso por Murcia (1785)

En el s. XIX se elaborarían dos proyectos de canalización fluvial destacados por el área geográfica donde se plantean, por la magnitud de los mismos y porque, a pesar de su detallada factura, nunca se desarrollarían en el momento de su planteamiento. Se trata de los proyectos de modificación de los cauces del Júcar y Segura, elaborados tras los desastres ocurridos en 1864 y 1879, respectivamente. En el primer caso, tras la colosal avenida de 1864, cuya memoria oficial daría lugar a uno de los primeros mapas oficiales de zonas afectadas existente en España (vid. infra), surgirían diversas propuestas de actuación que contemplaban la desviación del cauce del Júcar a su paso por algunas poblaciones de la Ribera baja, no exentas de polémica entre los habitantes de unas y otras localidades. Es el caso de la polémica surgida entre Algemesí y Alcira, en 1885 a raíz de una propuesta de desviación del

${ }^{2}$ El profesor Calvo García- Tornel ha llevado a cabo un brillante y agudo estudio del contenido de este proyecto de canalización del río Segura a su paso por la ciudad de Murcia. Vid. Calvo GarcíaTornel, F. (2005) "El proyecto de canalización y ornato del río Segura a su paso por Murcia (1785). Academia Alfonso X el Sabio, Murcia. (edición comentada). 
río publicada en el diario "El Eco de Júcar". En este caso no se aporta documento cartográfico, pero las descripciones de zonas con "riesgo" que se incluyen en la memoria ilustran sobre la localización de las mismas: "los fundamentos de este terror no pueden ser más justos. Estos son los propósitos de reunir en dos kilómetros, o sea en el espacio de dos mil metros, nada menos que el aterrador Júcar, el destructor Magro y el caudaloso río de los Ojos, espacio que frecuentemente lo inundan, llegando las aguas a cubrir las cimas de los árboles y alcanzando la altura de los pisos altos de las casas y los huertos. ¿Qué sucederá mañana si el Júcar se aproxima hasta el cauce del río de los Ojos?"3.

Por su parte en el Segura, tras la riada de Santa Teresa de 1879 y la de la Ascensión de 1884 se activaría la necesidad de llevar a cabo una serie de obras de defensa en el propio río Segura y en sus cauces más feroces a fin de evitar las devastadoras consecuencias de sus crecidas. Todo ello culminó con la redacción del "Proyecto de obras de defensa contra las inundaciones en el valle del Segura" (1886) de los ingenieros Ramón García y Luis Gaztelu, que resultó ser un ambicioso programa de obras sin apenas efecto en la protección de esta cuenca hidrográfica, puesto que sólo se desarrollaría en una mínima parte. Aunque, como en el caso anterior, la detallada memoria elaborada por ambos ingenieros no se acompañaría de un mapa de zonas afectadas por inundaciones o de localización de obras a llevar a cabo, algunos párrafos de la misma ilustran bien sobre el problema de las inundaciones ocasionadas por el río Segura y alguno de sus tributarios. Así, los ingenieros en relación con las áreas más conflictivas de la cuenca en relación con las crecidas de estos ríos señalan, "tendremos para ello presente que la zona más gravemente inundada es la confluencia del Guadalentín y el mar, donde se hallan las huertas de Murcia y Orihuela, dividiremos este examen en dos partes que son, la del Guadalentín hasta Murcia y la del Segura hasta su desembocadura, y esta división nos permitirá apreciar la parte con que cada una interviene en la producción del fenómeno y la consiguiente energía de los medios que deben de aplicarse"4.

Por último, otro tipo de referencias cartográficas indirectas de inundaciones constituyen, como se ha señalado, aquellos mapas que representan tramos bajos de aparatos fluviales, generalmente áreas de avenamiento precario, sobre los que se ha implantado asentamientos y actividad agraria (regadíos) que resultan afectados si acontecen crecidas fluviales. La cartografía existente es abundante en este caso, pero merece la pena destacar dos mapas de finalidad agrícola pero que representan sendas llanuras de inundación con ocasión de crecidas fluviales; se trata de los mapas de las llanuras aluviales del Júcar (1797) y Segura (primer tercio s. XIX); el primero incluido en las Observaciones del botánico Cavanilles que dibuja, de forma magistral, el "mapa de la Acequia Real del Júcar y valle de Cárcer", que corresponde con uno de los espacios inundables más importantes del tramo bajo del río Júcar (vid. figuras 4 y 5).

${ }^{3}$ Vid. Desviación del Júcar. Temores en Algemesí. Alcira, Imprenta de José Muñoz Ferriz, 1885.

${ }^{4}$ Vid. Proyecto de Obras de Defensa contra la Inundaciones en el Valle del Segura" por los ingenieros D. Ramón García y D. Luis Gaztelu, Murcia, Tipografía de las provincias de Levante, 1887. 
Figura 4. Mapa de la Acequia Real del Júcar y valle de Cárcer
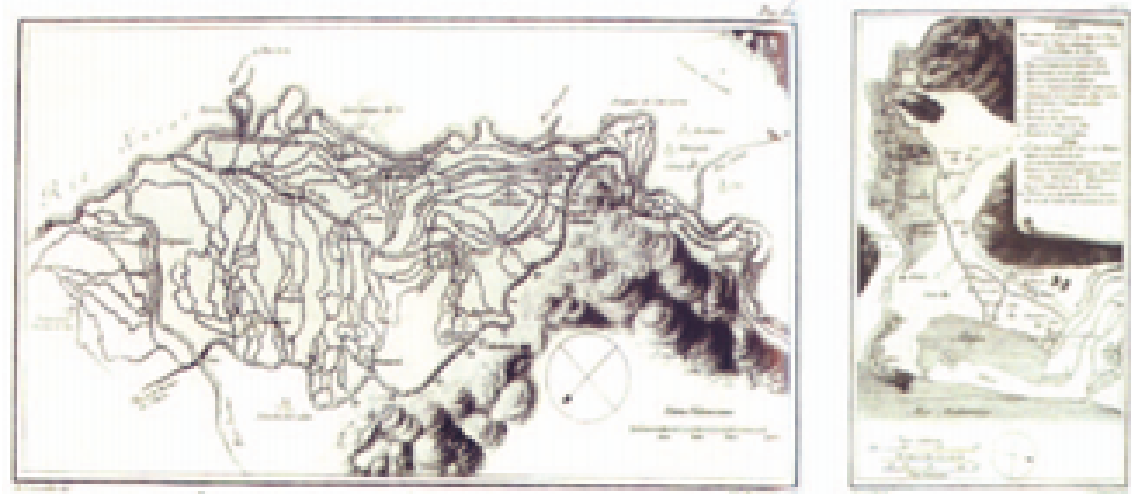

Fuente: A.J. Cavanilles, Observaciones, 1797

El segundo es un mapa de comienzos del siglo XIX con representación de la red de acequias y azarbes en la Vega baja del Segura, que refleja la doble circulación de aguas vivas y aguas muertas, implantada en época árabe para el riego de este espacio de huertas (vid. figura 5). En episodios de inundación, esta red de regadío actúa como sistema de difusión de las crecidas fluviales del río Segura que desborda su lecho mayor afectando áreas situadas a varias decenas de kilómetros del propio cauce fluvial.

Figura 5. Mapa del primer tercio del siglo XIX que refleja la doble circulación de aguas vivas y aguas muertas en el llano aluvial del Bajo Segura

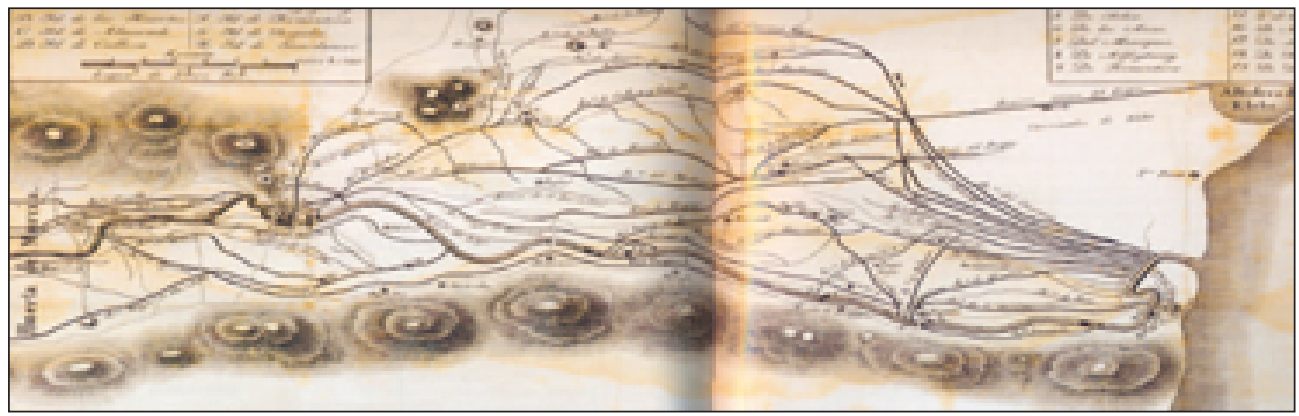

Fuente: La Cultura del Agua en la cuenca del Segura, exposición. Murcia, 2004

Resulta curioso señalar que en ambos casos, la zona cubierta por estas densas redes de riego representa el área que la cartografía oficial de riesgo de inundación elaborada a finales del s. XX en la Comunidad Valenciana (Plan de Acción Territorial para la reducción del riesgo de inundaciones en la Comunidad Valenciana) establece como espacios de alto riesgo ante inundaciones. 


\section{DE LOS MAPAS DE ZONAS AFECTADAS...}

Junto a las evidencias cartográficas que representan espacios afectados por las inundaciones, a partir del siglo XVIII la elaboración de informes y memoriales en relación con el desarrollo de un evento natural extremo (inundaciones), irá incluyendo mapas de las zonas afectadas por estos episodios. Se trata de mapas de zonas afectadas o cartografías de calamidad, que se elaboran a posteriori del episodio extraordinario.

Las características principales de estos mapas de zonas afectadas por una inundación, se resumen a:

-Se trata de cartografías elaboradas tras un evento importante. Se dibujan en informes elaborados para solicitud de auxilios o petición de obras que defiendan las poblaciones afectadas

-Tienen la precisión de la cartografía del momento. No son, por tanto, mapas de exactitud sino simples cartogramas, con indicación de zonas afectadas a modo de grandes manchas.

-A partir de mediados del s. XIX resulta frecuente que los informes o memorias sobre episodios de inundación importantes se acompañen de dibujos, imágenes y, con posterioridad, fotografías de las zonas afectadas.

Esta etapa de representación cartográfica de las inundaciones se inicia en el último cuarto del siglo XVIII y se prolonga prácticamente hasta nuestros días, puesto que el desarrollo de episodios de inundación importantes suele ir acompañada de la elaboración de informes oficiales de daños o, a partir de la segunda mitad del siglo XX, de trabajos de investigación donde se incluyen mapas de localización de áreas afectadas por los desbordamientos fluviales (vid. figura 6). En este prolongado período no hay, sin embargo, obligación legal de incluir mapas de zonas afectadas en los informes oficiales de daños por inundación; son, en este sentido, cartografías voluntarias.

Figura 6. Evolución histórica de las cartografías de inundación en España

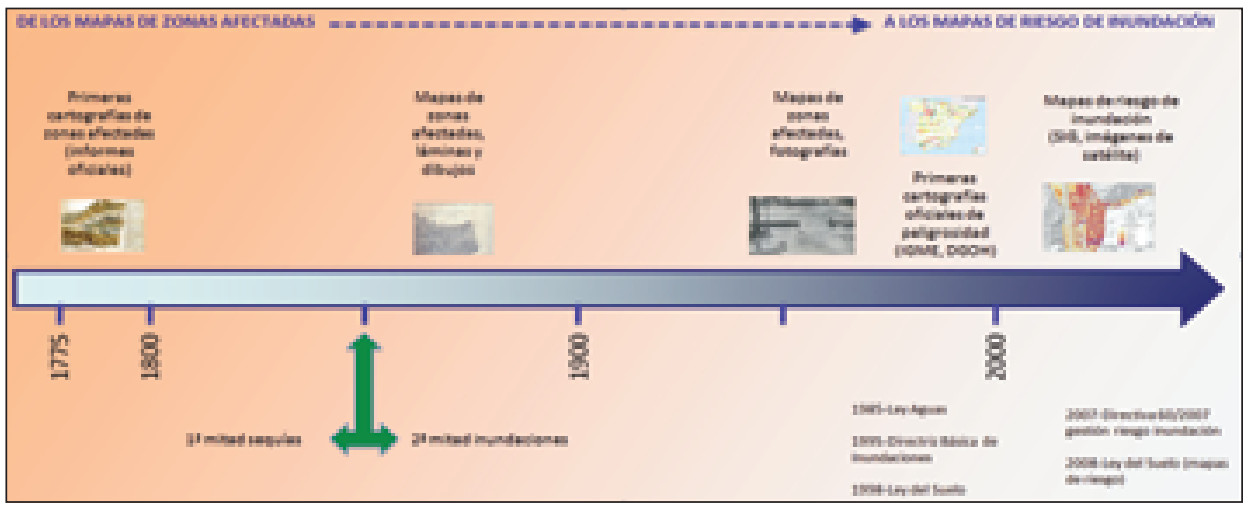

Fuente: Elaboración propia 
En el último cuarto del siglo XVIII comienzan a aparecer cartogramas que detallan áreas afectadas por episodios de inundación importantes. Se incluyen en informes o memorias donde se describen las consecuencias de desbordamientos ocurridos en ríos, arroyos, barrancos y ramblas. Pueden señalarse tres cartogramas como los primeros mapas de inundaciones en España; con la salvedad de que avances futuros en la investigación histórica ofrecerán nuevos documentos que permitirán enriquecer esta relación. Se trata del "Plano de la riera de Cànoves a su paso por Cardedeu y las inundaciones provocadas sobre el casco urbano" (1776-1777), del "Plano Topográfico..."de Josep Tormo (1797) donde se indican los "derrames en las maiores abenidas" en el alto Vinalopó y, por último, del mapa incluido en la Memoria sobre la inundación del Júcar en 1864, del ingeniero Miguel Bosch y Julia (Madrid, 1866).

El "Plano de la riera de Cànoves a su paso por Cardedeu y las inundaciones provocadas sobre el casco urbano" (1776-1777) es probablemente uno de los primeros mapas existentes en territorio peninsular con indicación de zonas inundables". En él se representa con un color azul claro el área de derrame de la riera de Cànoves hacia la población de Cardedeu, en el Vallés Oriental, tras los episodios de inundación ocurridos en 1776 y 1777. Especialmente este último fue virulento y dio lugar a la elaboración de un informe que incluía una descripción topográfica de la localidad y donde se adjuntaba el plano señalado, que se tiene como la primera referencia cartográfica del núcleo urbano de Cardedeu (vid. figura 7).

Figura 7. Plano de la riera de Cànoves a su paso por Cardedeu y las inundaciones provocadas sobre el casco urbano" (1776-1777) y detalle del núcleo urbano afectado
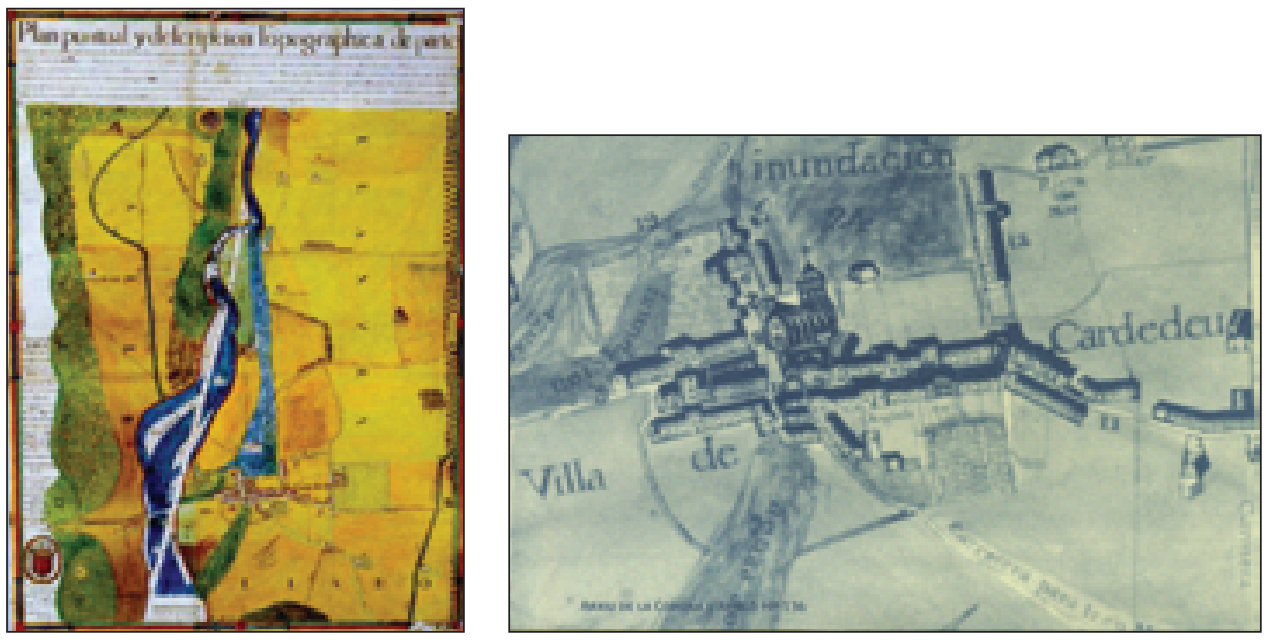

Fuente: Giménez Font, 2009 y www.cardedeu.cat

El "Plano Topográfico" de Josep Tormo representa el área de frecuente inundación existente en el valle de Beneixama (Alto Vinalopó, Alicante) debido a las dificultades de organización hídrica que presenta el río-rambla Vinalopó en su tramo alto, al 
discurrir por un área deprimida, con escasa pendiente, enclaustrada entre glacis que convergen hacia el fondo de una fosa procedentes de los asomos cretácicos del Camp de Mirra y de la sierra de San Cristobal (Gimenez Font, 2009). En estas condiciones las crecidas del Vinalopó terminaban configurando áreas extensas de avenamiento precario con encharcamiento e inundaciones duraderas en los campos de cultivo. El plano repoduce los "derrames en las maiores abenidas" del río Vinalopó sobre las huertas de Campo de Mirra y es seguramente el primer mapa existente con indicación de zonas inundables en el territorio valenciano (vid. figura 8).

Figura 8.- "Plano Topográfico..."de Josep Tormo (1797) donde se indican los "derrames en las maiores abenidas" en el alto Vinalopó

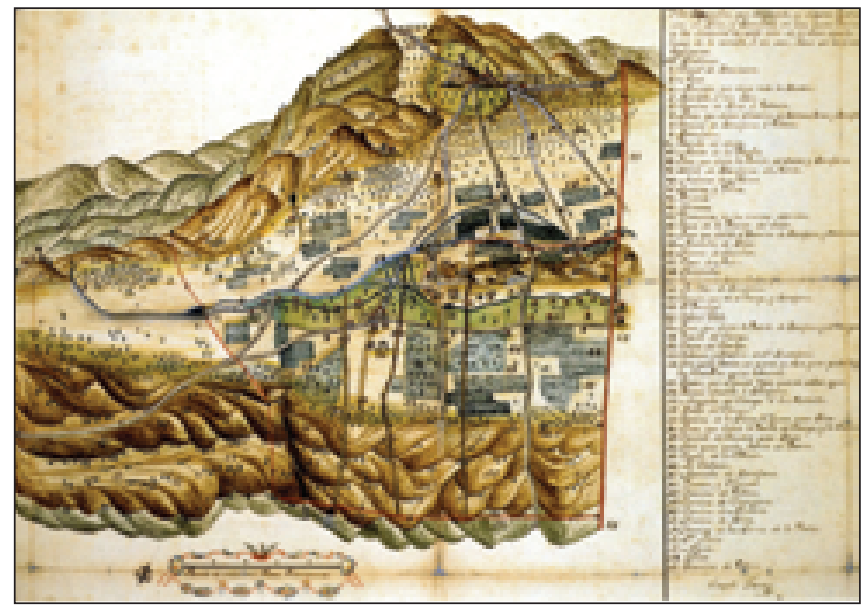

Fuente: Giménez Font, 2009

Tras la desastrosa avenida del Júcar, el de noviembre de 1864, que ocasionó numerosas víctimas mortales y cuantiosísimas pérdidas económicas en la ribera baja del río, se constituyó una Comisión de Estudio, encabezada por D. Miguel Bosch, ingeniero forestal. Se llevan a cabo actuaciones de socorro de las autoridades civiles y eclesiásticas: el arzobispo de Valencia, S. Mariano Barrio y Fernandez, ordena una rogativa por tres días consecutivos, cantando en cada uno de ellos una misa votiva proquacumque necessitate y la oración ad postulandam serenitatem. Estamos, en efecto, ante uno de los episodios más importantes ocurridos en la cuenca del Júcar en los últimos doscientos años, con registro de caudales máximos instantáneos calculados en 10.000-12.000 m3/s. A consecuencia de esta avenida, se formaría una nueva desembocadura en el río a 1,4 km. al sur de la anterior, en Cullera, que databa del año 1572. Dos años después de esta inundación, en 1866 se promulgaría la primera Ley de Aguas española, que incluyó indicaciones sobre la cuestión de inundaciones. En la Memoria sobre la inundación del Júcar de 1864, se incluyó un mapa -"Bosquejo de la Cuenca del Júcar"- en el que se indicaba, con una trama rayada, los "terrenos inundados" en la parte baja de la ribera del Júcar (vid. figura 9). 
Figura 9. Mapa de zonas afectadas por la inundación en la Ribera Baja del Júcar, incluido en la Memoria sobre la inundación del Júcar en 1864, del ingeniero Miguel Bosch y Julia (Madrid, 1866)

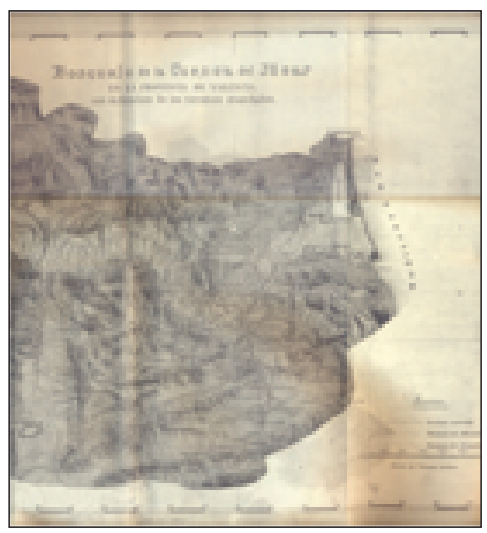

Fuente: Bosch y Julia, M. (1866) Memoria sobre la inundación del Júcar en 1864, Imprenta Nacional, Madrid, 1866. Disponible en: http://books.google.es/books?id=Og16XWB6SvgC $\&$ printsec $=$ frontcover\&hl $=$ es\&source $=\mathrm{gbs} \_g e \_s u m m a r y \_r \& c a d=0 \# \mathrm{v}=$ onepage $\& \mathrm{q} \& \mathrm{f}=$ false

Como se ha indicado, en la segunda mitad del siglo XIX, será frecuente la publicación de memorias e informes sobre inundaciones importantes ocurridas en nuestro país, que se acompañarán de láminas con dibujos a mano alzada que representan los efectos de dichas avenidas fluviales en el ámbito afectado. Así en la Memoria histórica de la inundación de la Ribera de Valencia en los días 4 y 5 de noviembre de 1864, de D. Vicente Boix (1865), se incluyen una serie de láminas con las consecuencias de la crecida del río en diversas poblaciones de la Ribera baja (vid. figura 10).

Figura 10. Efectos de la inundación del Júcar de 1864 en la Ribera baja y detalle de la altura de las aguas alcanzada en la localidad de Alcira

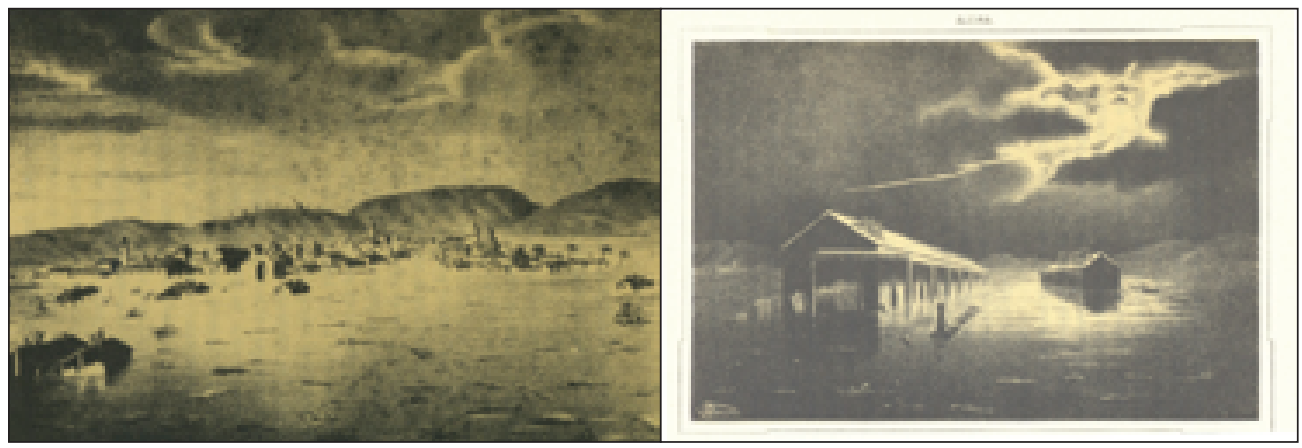

Fuente: Memoria histórica de la inundación de la Ribera de Valencia en los días 4 y 5 de noviembre de 1864, Valencia, imprenta de La Opinión, 1865 
Como en el caso de la inundación del Júcar de 1864, la famosa "riada de Santa Teresa" en la cuenca del Segura (14-15 de octubre de 1879), originó numerosos documentos gráficos sobre sus terribles efectos. De nuevo se trata de uno de los episodios de inundación más destacados ocurridos en la segunda mitad del siglo XIX en España. Las intensas lluvias acumuladas en la cuenca del Segura y, en especial, en su afluente más torrencial, el Guadalentín, ocasionaron una crecida salvaje en la cuenca media y baja. Protagonismo destacado tuvo, como se ha señalado, el rio-rambla Guadalentín, que alcanzó un pico máximo de crecida de $1.500 \mathrm{~m} 3 / \mathrm{s}$. La onda de crecida tardó 7 horas en llegar de Lorca a Murcia. El resultado fue devastador: 777 víctimas mortales y cuantiosas pérdidas en agricultura, viviendas y mobiliario urbano. El episodio alcanzó gran repercusión nacional e internacional. Se editó el número único de la revista París-Murcia que contó con la participación de artistas franceses de la época, entre las que destacaban las ilustraciones de Gustavo Doré. En el volumen se incluían dibujos de gran interés sobre las consecuencias de la grandiosa crecida del río Segura en la ciudad de Murcia y su huerta, así como en la localidad de Orihuela, en su vega baja (vid. figura 11).

Figura 11. Efectos de la riada de Santa Teresa, en la cuenca del Segura (1879). Ilustraciones incluidas en el número único de la revista París-Murcia, editada con motivo del desastre
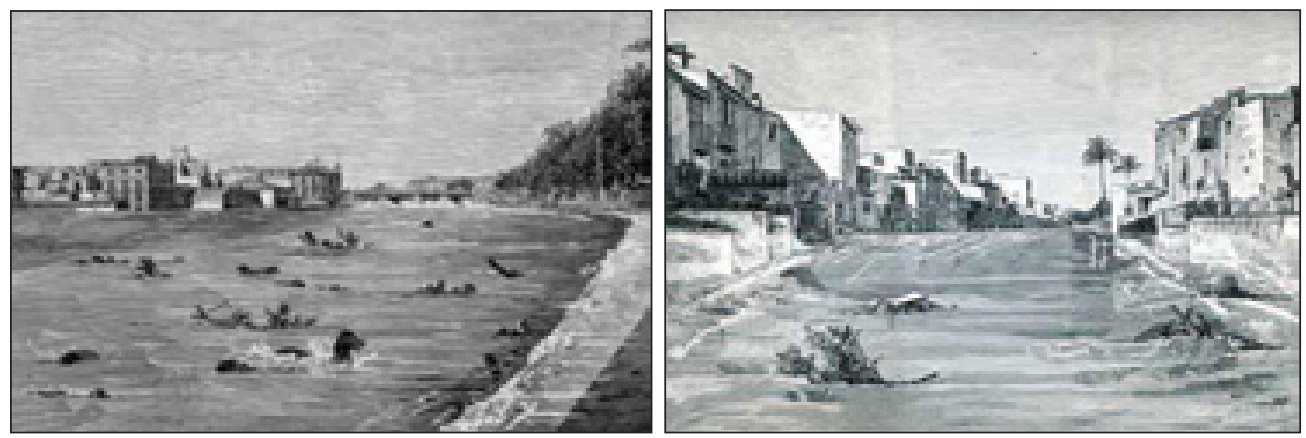

Fuente: www.regmurcia.com

A raíz de este episodio y de la riada de la Ascensión de 1884, se celebraría, en marzo 1885, el "Congreso contra las inundaciones de la región de Levante", se crearía, asimismo, una comisión para el estudio de los desastrosos efectos de las reiteradas riadas y, por último, se elaboraría el citado "Proyecto de obras de defensa contra las inundaciones en el valle del Segura" (1886), de los ingenieros Ramón García y Luis Gaztelu que nunca se llevaría a efecto (vid. supra).

A lo largo del siglo XX, a las ilustraciones y dibujos que atestigüan los efectos de inundaciones, se sumarían las fotografías. Sin duda, el episodio de inundación de mayor repercusión socio-política de la España del franquismo, fue la riada del Turia en Valencia, el 14 de octubre de 1957. Una tormenta intensa de otoño, generada por la instalación de un embolsamiento de aire frío en altitud sobre el Estrecho de Gibraltar, ocasionaría valores de precipitación máximo por encima de $300 \mathrm{~mm} . / 24 \mathrm{~h}$. sobre Va- 
lencia y las poblaciones circundantes de la Horta. El río Turia, experimentó dos momentos de crecida, uno en la madrugada del día 14 de octubre y otro, más virulento, a primeras horas de la tarde de aquella jornada. En este segundo, se ha calculado un caudal máximo instantáneo de $3.700 \mathrm{~m} 3 / \mathrm{s}$ a su paso por la capital. El desbordamiento del Turia en la ciudad de Valencia y en las poblaciones próximas fue de gran magnitud, generando unos daños económicos evaluados en 4.000 millones de pts (pts. corrientes) por la Comisión Técnica Especial constituida a tal efecto y la pérdida de 86 vidas humanas. El diario Las Provincias publicó un número especial con motivo de este desastre natural, que incluía numerosas fotografías sobre los efectos de la riada en la ciudad de Valencia y las poblaciones aledañas de la Huerta (vid. figura 12).

Figura 12. Fotografías y postales de los efectos de la riada del Turis en Valencia, 14 de octubre de 1957
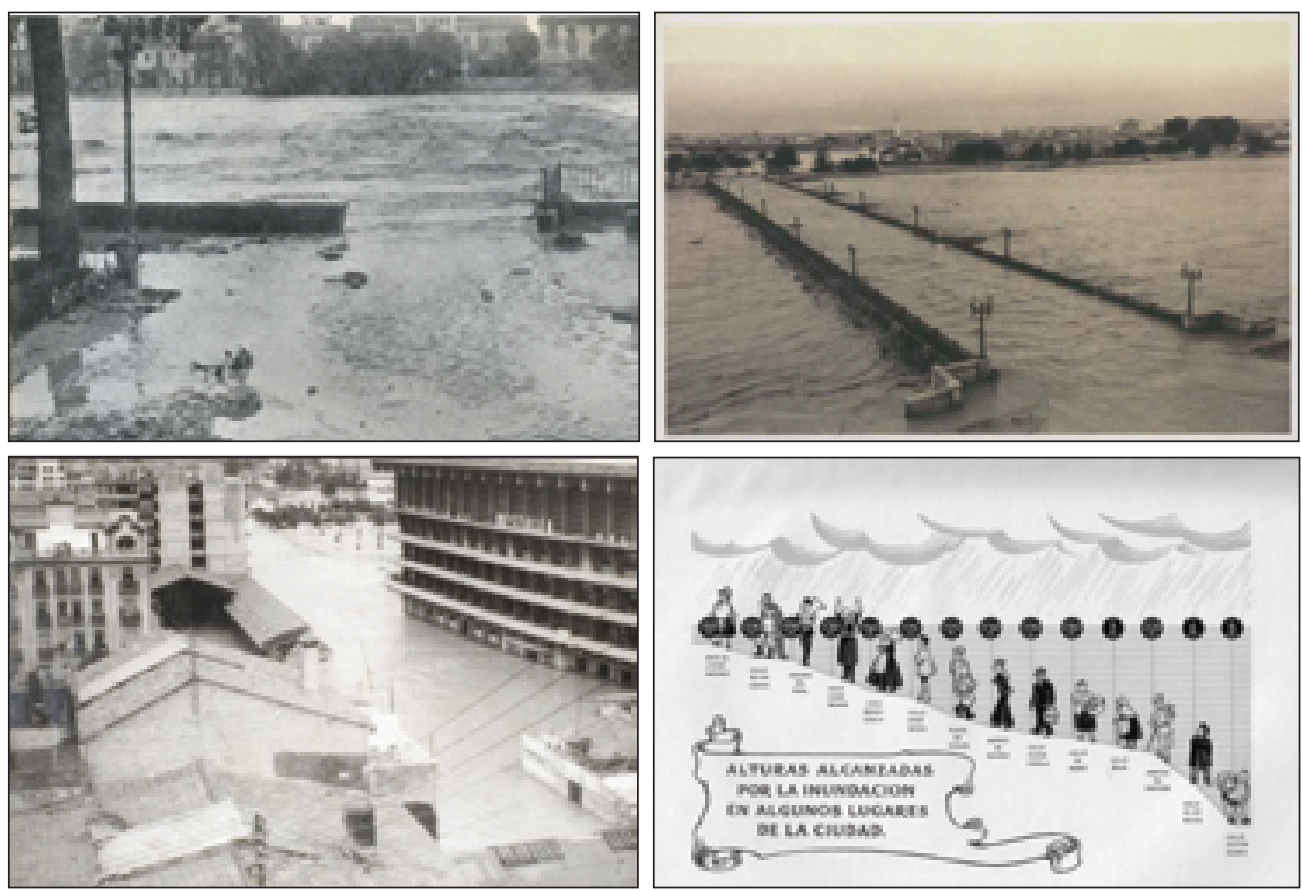

Fuente: La Riada del Turia, número especial del diario Las Provincias

El informe de daños que se elaboró desde Gobernación Civil se incluía un cartograma con el área afectada por la inundación y que ha sido incluido y tratado en el recién editado Atlas Estratégico de la ciudad de Valencia ${ }^{5}$ (vid. figura 13).

${ }^{5}$ Vid. Hermosilla Pla, J. (dir.) (2010) Atlas Estratégico. Valencia. Ayuntament de Valencia y Universitat de València, Valencia, 195 pp. 
Figura 13. Efectos de la riada del río Turia en Valencia, el 14 de octubre de 1957

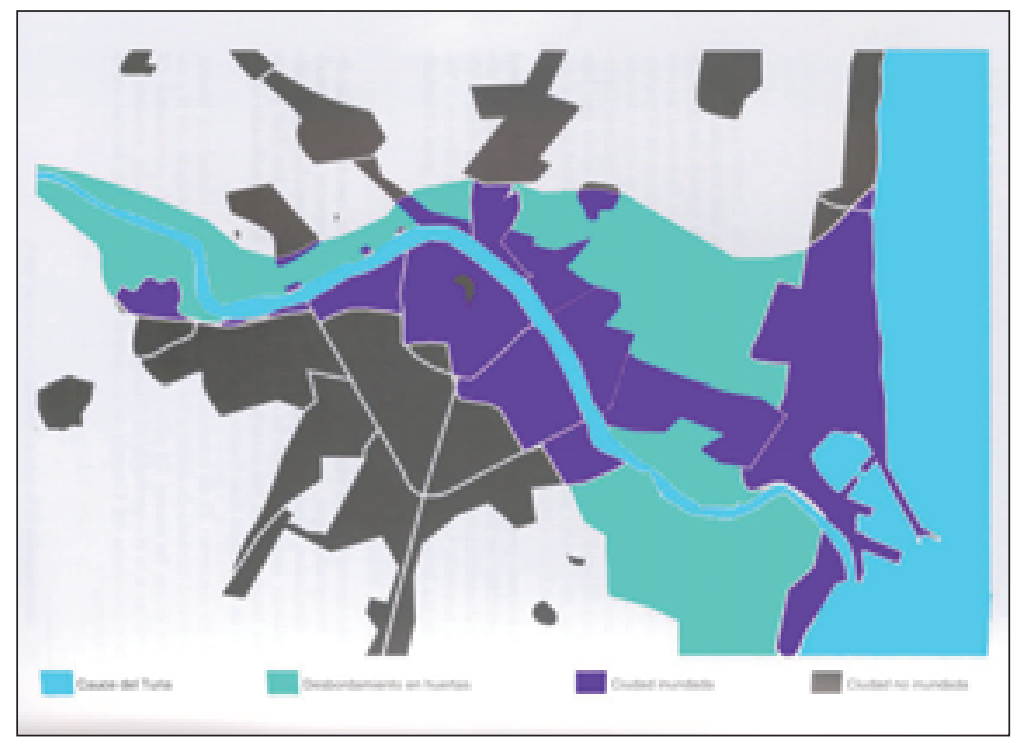

Fuente: Hermosilla Pla, J. (dir.) Atlas Estratégico. Valencia (2010)

Como resultado de los graves efectos de este episodio en la ciudad de Valencia se aprobaría, nueve meses después de la tragedia, el denominado "Plan Sur" que supuso la construcción de un nuevo cauce en el tramo final del río Turia que evitara futuras inundaciones en la ciudad. Es una de las actuaciones estructurales más importantes llevadas a cabo en España en la segunda mitad del siglo XX y que supuso un cambio en la evolución urbana de la ciudad de Valencia.

Otro episodio de gran repercusión en la España franquista fue el ocurrido en septiembre de 1962 en la cuenca baja del río Llobregat. Se trata del evento de inundaciones que más víctimas provoca a lo largo del siglo XX (973 muertes $\left.{ }^{6}\right)$, además de cuantiosos daños materiales (5.000 viviendas destruidas). El desarrollo, durante la jornada del 25 de septiembre, de unas condiciones de fuerte inestabilidad en el noreste peninsular, favoreció la génesis de un potente núcleo de tormenta que descargó cerca de 300 litros en pocas horas en extensas zonas del centro de Cataluña. La precipitación acumulada en $24 \mathrm{~h}$ fue superior a $60 \mathrm{~mm}$ en casi todas las Cuencas Internas de Cataluña, superándose los $200 \mathrm{~mm}$ (250 mm en Martorelles) en la parte baja de las cuencas del Besós y del Llobregat (Comarcas del Vallés, del Baix Llobregat y del Barcelonés). El resultado fue la crecida de los ríos Ripoll, riera de Rubí, Besós y es-

${ }^{6}$ Llasat Botija ofrece los siguientes datos de víctimas a consecuencia de este episodios de lluvias torrenciales: 441 muertos, 374 desaparecidos y 213 heridos. (Vid. Llasat Botija, M.C. "El episodio del 25 de septiembre de 1962", en Revista del Aficionado a la Meteorología. Disponible en http://www. meteored.com/ram/352/el-episodio-del-25-de-septiembre-de-1962/ 
pecialmente, del Llobregat que se llevó por delante campos de cultivo, instalaciones fabriles y viviendas en su tramo bajo. Las fotografías que publicaron diversos diarios catalanes con los efectos de aquel raudal de agua son expresivas de la magnitud de la catástrofe (vid. figura 14)

Figura 14. Efectos del desbordamiento catastrófico del río Llobregat en septiembre de 1962

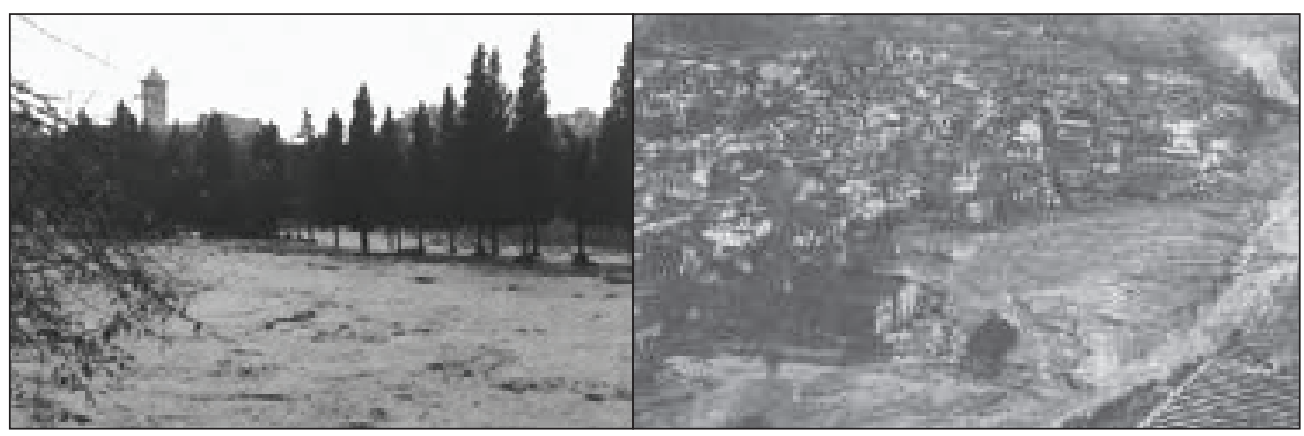

Fuente: meteored.com

Por su parte, no hay mapa oficial de áreas inundadas por las crecidas de los ríos del sector central de Cataluña a consecuencia de las tormentas del 25 de septiembre; tan sólo un cartograma que difundieron los diarios catalanes de la época en las siguientes jornadas tras el desastre (vid. figura 15).

Figura 15. Mapa de zonas afectadas por la inundación de septiembre de 1962 en la provincia de Barcelona

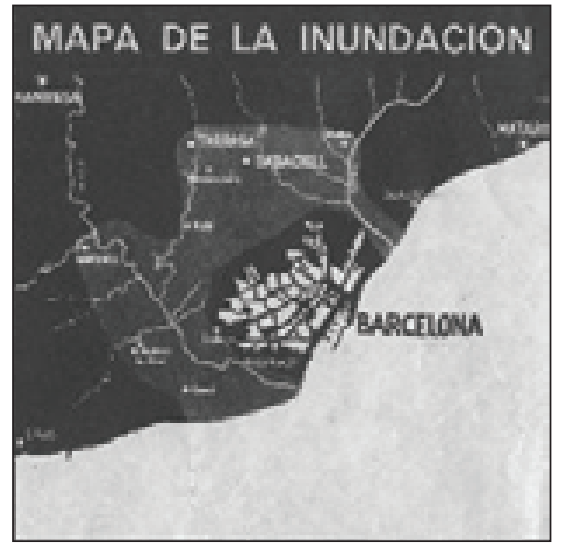

Fuente: diario La Vanguardia

Un mapa algo más preciso de zonas afectadas fue el elaborado por el Instituto para la Reforma y Desarrollo Agrario a consecuencia de las terribles crecidas de aparatos 
fluviales en el sureste peninsular ocurrido entre el 19 y 21 de octubre de 1973. Una situación típica de "gota fría" ocasionó la descarga de lluvias torrenciales en diversos puntos del sureste peninsular, registrándose uno de los record de lluvia máxima diaria de España ( $600 \mathrm{~mm} / 24$ h. en Albuñol y Zurgena). En la cuenca del Segura, la rambla de Nogalte, el río-rambla Guadalentín y el propio Segura fueron los protagonistas de un episodio de inundación que ocasionó, sólo para las provincias de Murcia y Alicante, daños valorados en 948 millones de pesetas. Debido a los elevados daños en el campo (campos anegados, cosechas perdidas) el IRYDA elevó informe al Gobierno incluyendo el mencionado mapa con indicación de las zonas afectadas (vid. figura 16).

Figura 16. Zonas de la cuenca del Segura afectadas por las inundaciones de octubre de 1973

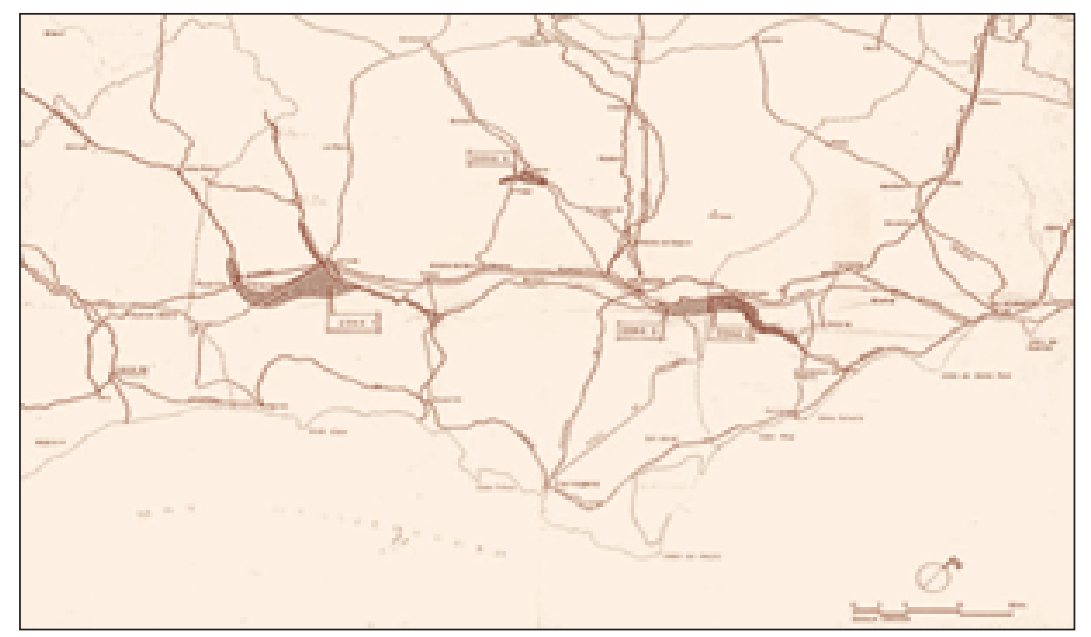

Fuente: IRYDA

La década de los años ochenta conoció múltiples episodios de inundación, de gran repercusión socio-económica, en España. No obstante la inclusión de cartografía de zonas afectadas seguía siendo escasa en ellos al no haber obligación legal. Un dato significativo es que a partir de este momento será abundante la incorporación de fotografías en color de efectos de las inundaciones, que se incorporan, como anexo, a los informes oficiales de daños.

Tres de estos episodios de inundación destacan sobremanera por las graves consecuencias que de ellos derivaron. El primero en octubre de 1982, cuando una "gota fría" muy activa ocasionó la rotura de la presa de Tous y un desbordamiento colosal del Júcar en su tramo bajo que anegó la totalidad de campos y poblaciones situadas en la llanura aluvial de este río hasta la desembocadura. Un dato de interés en este episodio es la aparición de fotografía en color de las consecuencias de la avenida del Júcar en las poblaciones de la Ribera Baja afectadas por la colosal avenida del río y la rotura de la presa de Tous (vid. figura 17). 
Figura 17. Efecto de la avenida del Júcar, en octubre de 1982. Rotura de la presa de Tous e inundaciones en la localidad de Alcira
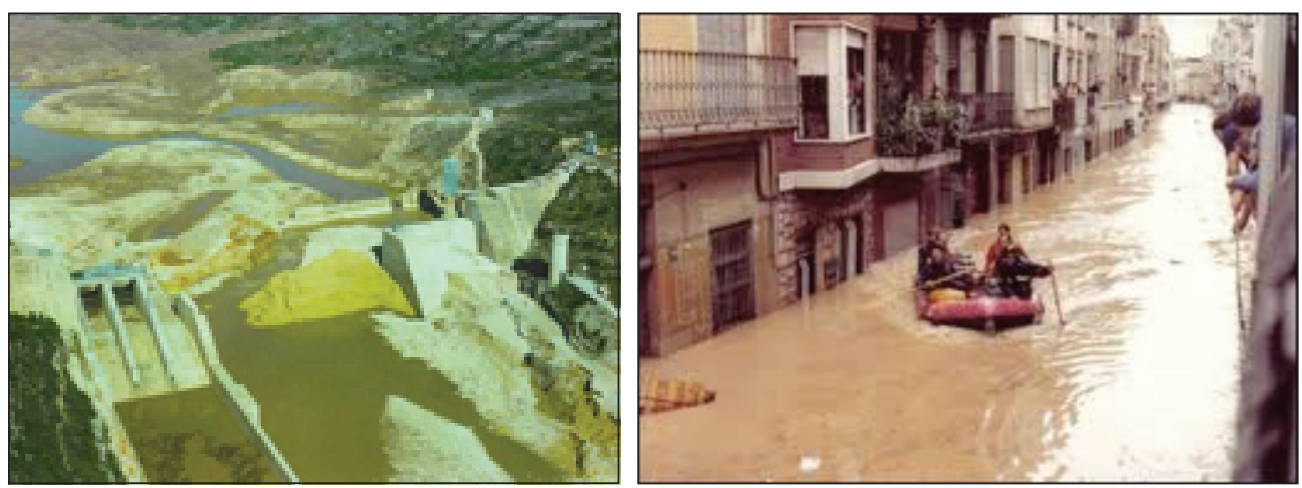

Fuente: Paisajes Españoles y Revista del Aficionado a la Meteorología (disponible en:www. tiempo.com)

El Informe oficial de este episodio de inundación elaborado por el Ministerio del Interior, apenas incluía un mapa de puntos con los tramos de carretera de la provincia de Murcia afectados por las crecidas fluviales en la cuenca del Segura ${ }^{7}$. De la descripción de zonas afectadas se elaboraron unos cartogramas que fueron recopilados, en 2003, en una publicación editada por una asociación cultural de Alzira ${ }^{8}$ (vid. figura 18).

Figura 18. Mapa de zonas afectadas por la "Pantanada de Tous" de octubre de 1982

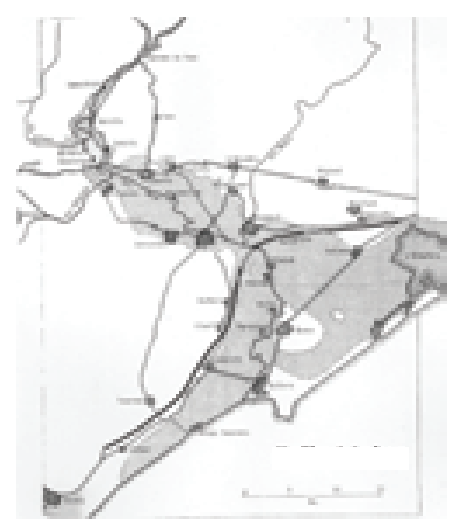

Fuente: Asociación Cultural Malva, Alzira, 2003

${ }^{7}$ Vid. Ministerio del Interior (1982) Informe Inundaciones provincias de Albacete, Alicante, Murcia y Valencia. Madrid.

${ }^{8}$ Vid. Asociación Cultural Falla Plaça de la Malva (2003). Fins ací arribá l'aigua de la pantanada de 1982. Alzira. 
Pero, sin duda, el suceso que mayores pérdidas económicas ocasionó en este decenio fue la riada ocurrida en el País Vasco en agosto de 1983 que, además, es el episodio que mayores daños valorados ha conocido el territorio español en la segunda mitad del siglo XX. Lluvias torrenciales en el País Vasco, Navarra Atlántica y la mitad oriental de Cantabria, que llegaron a ocasionar registros máximos de $500 \mathrm{~mm} / 24 \mathrm{~h}$. en la ría de Bilbao (Larrasquitu) en la jornada de 26 de agosto, causaron la crecida desaforada de ríos y arroyos con desbordamientos en numerosos nucleos de población, incluida la capital vizcaína que soportó los peores efectos. A raíz de este episodio de lluvias torrenciales e inundaciones se registraron 34 victimas mortales y 5 desaparecidos y unas pérdidas valoradas en 200.000 millones de pesetas (corrientes).

En el estudio "Las inundaciones en la España Peninsular" (1988) (vid. infra.) se incluyó un mapa de las zonas afectadas por la inundación de agosto de 1983 en la cuenca Norte (vid. figura 19), puesto que junto al País Vasco que sufrió los daños más importantes, otras cuencas fluviales del norte de España experimentaron grandes crecidas y desbordamientos. Con posterioridad, la Agencia Vasca del Agua ha elaborado una cartografía oficial de zonas afectadas por este episodio de inundación?.

Figura 19. Mapa de zonas afectadas por las inundaciones de agosto de 1983 en el País Vasco

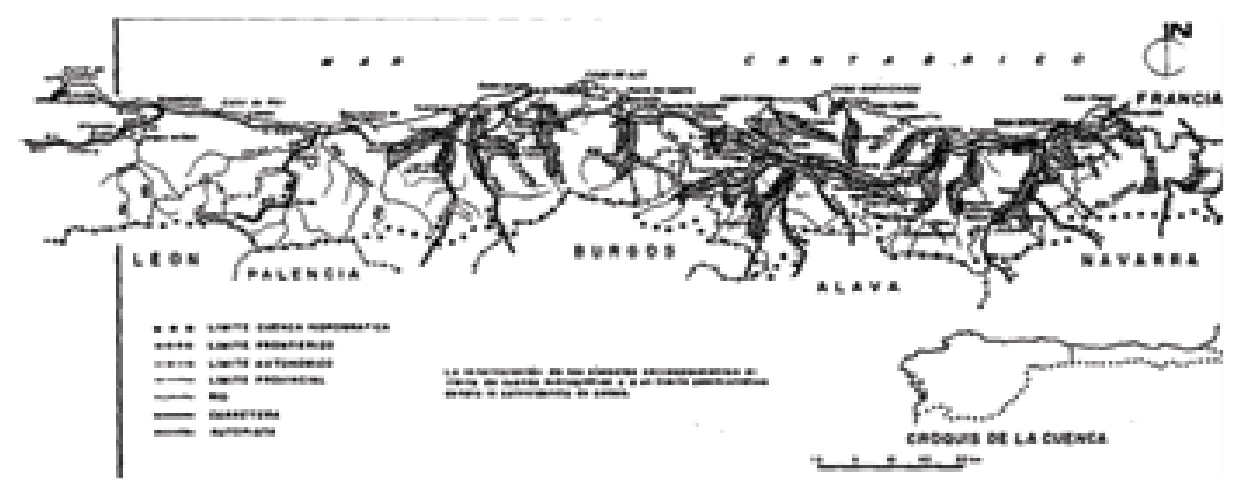

Fuente: MOPU y DGPC. "Las inundaciones en la España peninsular"

Por último, la crecida del Júcar de comienzos de noviembre de 1987 ocasionó la última gran inundación padecida en la Ribera Baja en los últimos decenios. Lluvias torrenciales que rebasaron los $800 \mathrm{~mm} / 24 \mathrm{~h}$. en algún punto del sur de la provincia de Valencia causaron un impetuoso aluvión que anegó campos y ciudades en el tramo bajo del río hasta su desembocadura. En esta ocasión la Confederación Hidrográfica del Júcar elaboró un mapa de zonas afectadas, que se incluyó, posteriormente, en el proyecto de defensa de avenidas del río Júcar, que no se ha llevado a término (vid. figura 20).

${ }^{9}$ Vid. http://www.uragentzia.euskadi.net/u81-0003/es/contenidos/informacion/cartografia/es_cartogra/inundabilidad.html 
Figura 20. Mapa de zonas afectadas por la crecida del río Júcar en noviembre de 1987. Octubre de 1982

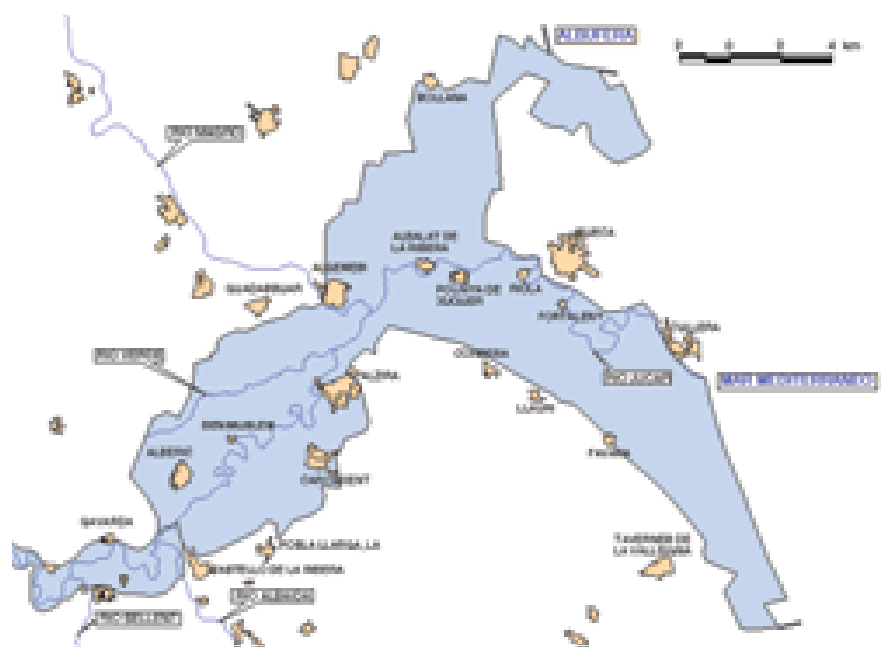

Fuente: CHJ

\section{4. ... A LOS MAPAS DE RIESGO DE INUNDACIÓN}

Los avances conceptuales y de método que experimenta la disciplina del riesgo en la segunda mitad del siglo XX, se van a plasmar, asimismo, en los mapas de inundaciones representados. Se consolida el concepto de riesgo natural como probabilidad de afección de un hecho físico (peligro natural) sobre una población (vulnerabilidad) que ocupa un territorio (exposición). De manera que estos tres elementos integrantes del riesgo pasan a ser componentes básicos de la cartografía de riesgo.

Los rasgos que definen los mapas de riesgo de inundación se sintetizan en:

-Son mapas elaborados "a priori”, que caracterizan espacios geográfico en función de la probabilidad de que acontezca un evento natural extremo (inundación).

-Existe diversidad de criterios de elaboración: histórico, estadístico, percepción.

-Tienen gran precisión. En la actualidad, se manejan casi exclusivamente sistemas de información geográfica por la versatilidad y capacidad de actualización que permiten a la hora de tratar la información a representar.

-La elaboración de estos mapas maneja escalas cada vez "más grandes" (uso urbanístico)

-Se utilizan imágenes de satélite como base cartográfica y sobre ella dibujan las diferentes tramas.

-La elaboración de estos mapas encuentra en el colectivo geográfico al profesional más capacitado para llevarlos a efecto. Debe recordarse que el análisis del riesgo natural 
comenzó como disciplina de estudio dentro de la geografía (años cuarenta del siglo $\mathrm{XX}$ ) y es en esta ciencia donde ha encontrado un desarrollo conceptual y de método más maduro.

Tal vez, el valor más importante de los mapas de riesgo de inundaciones es su condición de pieza básica para la planificación territorial. La implantación de usos en el territorio requiere, como condición previa, la elaboración de análisis detallados del medio físico donde se estudien los recursos y los riesgos asociados a la dinámica del mismo. Estos análisis deben ir acompañados de cartografía, como herramienta cartográfica fundamental del proceso planificador. En España este procedimiento no ha sido de obligado cumplimiento hasta la promulgación de la Ley del Suelo de 2008, cuyo artículo 15.2 señala que "el informe de sostenibilidad ambiental de los instrumentos de ordenación de actuaciones de urbanización deberá incluir un mapa de riesgos naturales del ámbito objeto de ordenación". De manera que ni la Directriz Básica de Inundaciones (1995) ni la Ley del Suelo de 1998 pudieron frenar la ocupación de espacios inundables por parte de los usos urbanos o de infraestructuras. Y ello porque la elaboración de cartografía de riesgo, como documento de acreditación del riesgo, no era una exigencia sino una recomendación. La implementación de la obligación de elaborar mapas de riesgo que incluye la vigente Ley del Suelo de 2008 va a depender, sin embargo, del interés en llevar a cabo una adaptación más o menos rápida de este texto legal en las Comunidades Autónomas.

Esta etapa arranca en el decenio de los años ochenta del pasado siglo y se prolonga hasta la actualidad. Debe señalarse que en este período se siguen elaborando mapas de zonas afectadas por inundaciones, como se ha indicado (vid. supra), pero el avance en los métodos de representación cartográfica y la promulgación de normativas sectoriales (protección civil, agua, suelo) donde se contienen preceptos para la preparación de cartografías de riesgo como medida de reducción del riesgo va a imponer un impulso fundamental en el desarrollo de mapas de riesgo de inundación.

En España la cartografía de riesgo de inundaciones ha estado muy condicionada por la consideración legal de los espacios inundables en la legislación de agua. Recordemos que desde 1975 la normativa de aguas incorporó el criterio del "período de retorno" para la determinación de las áreas inundables ${ }^{10}$. Ello ha supuesto que los mapas de inundaciones fueran, básicamente, mapas de peligrosidad frente a las inundaciones. Sólo a partir de los años noventa del pasado siglo comenzaría la elaboración de verdaderos mapas de riesgo de inundación con incorporación de tratamiento de los

${ }^{10}$ El Decreto de 18 de septiembre de 1975 (B.O.E. de 25 de octubre), que incluía una modificación puntual de las funciones definidas para la policía de aguas en España, reviste particular interés para el estudio de las inundaciones y su tratamiento normativo en nuestro país. Entre los aspectos más destacados de su contenido se contiene la regulación de la zona inundable en los cauces que pasa a estar definida como "la zona delimitada por la línea que alcancen las avenidas cuyo período de retorno sea de 500 años". Se recoge en este Decreto el parámetro de los 500 años de período de retorno incluido ya en la Instrucción para el proyecto, construcción y explotación de grandes presas promulgada de 1967 (Orden del Ministerio de Obras Públicas de 31 de mayo de 1967. BOE de 27 de octubre). Este mismo criterio (500 años) se mantendrá en las legislaciones de agua promulgadas en España en época democrática hasta nuestros días. 
usos del suelo existentes y previstos en un territorio, requisito fundamental para que un mapa pueda considerarse cartografía de riesgo.

Los primeros mapas de riesgo de inundación que se elaborarán en España corresponden a las cartografías realizadas por el Instituto Geológico y Minero de España que, en los años ochenta del siglo pasado, desarrolla una serie de estudios sobre avenidas fluviales e inundaciones dentro de la recién creada área de investigación en riesgos de la naturaleza, coordinada por Francisco Ayala-Carcedo ${ }^{11}$. Nunca se agradecerá bien en España el enorme impulso que supuso la labor de Ayala-Carcedo para la disciplina de riesgo y, especialmente, para el desarrollo del análisis de riesgo natural y de su cartografía en la planificación territorial. Realmente estos mapas de riesgo elaborados por el grupo de trabajo de riesgos naturales del IGME eran básicamente cartografías de peligrosidad ante inundaciones, aunque en los informes que acompañaban a los mapas se incluía análisis de usos del suelo y se determinan niveles de riesgo.

A raíz de las desastrosas inundaciones de 1982 (Júcar-Pantanada de Tous) y 1983 (País Vasco) el Ministerio de Obras Públicas (Dirección General de Obras Hidráulicas) y Protección Civil, pusieron en marcha la elaboración de un estudio magno sobre "Las Inundaciones en la España Peninsular" que incluía una revisión histórica de las inundaciones ocurridas en las diferentes cuencas hidrográficas peninsulares y una evaluación de las zonas con riesgo potencial de inundaciones. El estudio tardó un lustro en editarse (1988), debido a la gran cantidad de documentación que debía consultarse en los archivos de las confederaciones hidrográficas. Se trata del estudio más completo llevado a cabo por la Administración en este sentido, que incluía asimismo mapas de inundación, a escala estatal y por cuencas hidrográficas. Como aspecto negativo de este interesante trabajo, cabe señalar la exclusión de los dos archipiélagos de la zona de estudio, siendo estos territorios espacios ambos con riesgo de inundación destacado, especialmente en el caso canario. La figura adjunta recoge los dos mapas síntesis sobre riesgo de inundaciones en España, donde se localizaban los puntos conflictivos (núcleos de población) y los tramos de cauce fluvial con indicación de su nivel de riesgo (vid. figura 21).

${ }^{11}$ Vid., entre otros, Ayala-Carcedo, F.J. y Pérez González, A. (dir.). (1984). Establecimiento de criterios geológicos para la prevención de daños por avenidas. Aplicación a las inundaciones del Valle del Nervión (País Vasco) en agosto de 1983. Instituto Geológico y Minero de España, Madrid, 86 pp.; Durán Valsero, J.J., Eliazaga Muñoz, E., Garzón Heydt, G., Lamas Romero, J.L., Lendínez González, A., Prieto Alcolea, C. y Ayala-Carcedo, F.J.(1985). Geología y prevención de daños por inundaciones. Instituto Geológico y Minero de España, Madrid, 421 pp.; Ayala-Carcedo, F.J. (dir.) (1986). Estudio geológico para la previsión de riesgos por inundaciones en el País Vasco. Informe técnico IGME 00874, 53 pp.; Ayala-Carcedo, F.J. (1986). Estudio geológico para la previsión de riesgos por inundaciones en el País Vasco, Álava y Vizcaya y el condado de Treviño E. 1:100000. Instituto Geológico y Minero de España, Madrid, 71 pp.; Ayala-Carcedo, F.J., Rodríguez Ortiz, J.M., Prieto Alcolea, C., Durán Valsero, J.J., Lamas Romero, J.L. y Rubio Amo, J. (1986). Mapa previsor de riesgos por inundaciones en núcleos urbanos de Andalucía y Extremadura: Almería, Andújar, Badajoz, Barbate, Campo de Gibraltar, Córdoba, Écija, El Ejido, Granada, Guadix, Loja, Lucena, Málaga, Mérida, Puente Genil, Utrera. Instituto Geológico y Minero de España, Madrid, 205 pp. 
Figura 21. Mapa de puntos conflictivos y de zonas con riesgo potencial de inundaciones en España peninsular
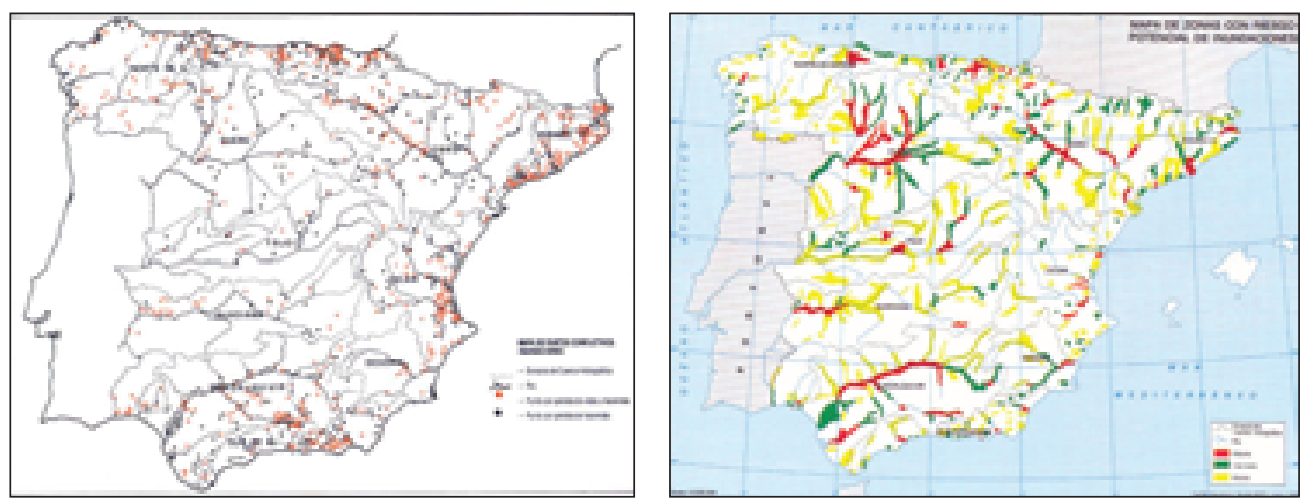

Fuente: Informe Las Inundaciones en la España Peninsular, D.G. Protección Civil y DHOH, Ministerio de Obras Públicas y Transportes, 1988

El Informe se acompañaba de un "Mapa de inundaciones Históricas" en las diferentes cuencas hidrográficas, donde se localizaban los núcleos de población conflictivos por la recurrencia en el desarrollo de inundaciones y se explicaba, en un recuadro de texto, las causas "urbanísticas" de las mismas (vid. figura 22).

Figura 22. Mapa de inundaciones históricas de la cuenca del Segura

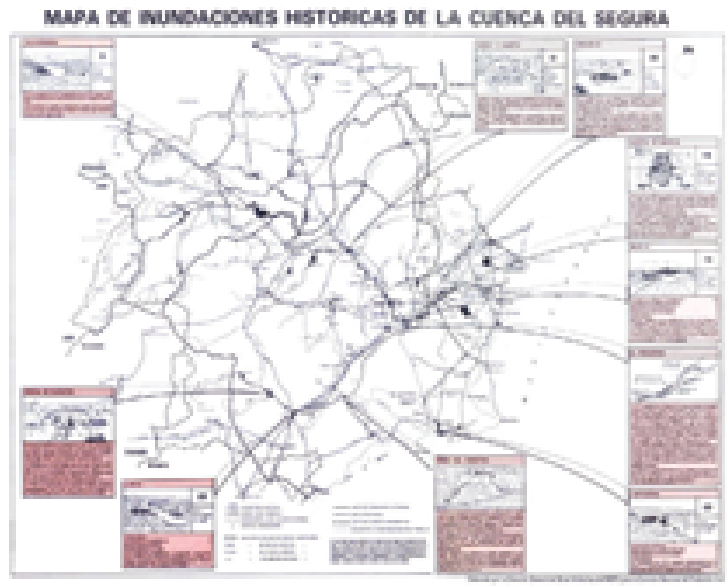

Fuente: Informe Las Inundaciones en la España Peninsular, D.G. Protección Civil y DHOH, Ministerio de Obras Públicas y Transportes, 1988 
Este trabajo establecerá un antes y un después en la elaboración de cartografía de inundaciones en España, al ser la primera referencia cartográfica oficial, de escala estatal, sobre espacios con riesgo de inundación, que podrá usarse como documento de acreditación del nivel de peligrosidad de un territorio. A ello seguiría la promulgación de la Directriz Básica de Inundaciones de Protección Civil (1995) donde se recomendará la elaboración de mapas de riesgo en los planes de emergencia de escala regional y local y se establecerán criterios para su elaboración. Cuestión distinta es el desigual ritmo de elaboración de estos planes de emergencia ante inundaciones desarrollado en nuestro país, especialmente en la escala local, donde un $80 \%$ de los municipios españoles todavía carecen de este tipo de documento.

Pero, sin duda, el gran avance de la cartografía de riesgo de inundación en España se producirá tras el desastre del camping de Biescas, en agosto de 1996. El impacto social que causó la tragedia de Biescas ( 87 muertos) motivó la creación de una Comisión especial sobre desastres en el Senado que funcionó hasta 1998 y entre cuyas conclusiones se señaló la necesidad de elaborar un banco de datos estatal de cartografía de riesgo de inundación. Este aspecto sólo se desarrollará diez años después en cumplimiento de la Directiva 60/2007 de gestión de inundaciones en el territorio europeo. Otra disposición de esta Comisión del Senado fue la modificación de la legislación del suelo para incluir articulado que impidiese la ocupación con usos urbanos de áreas con riesgo natural. Ello dio lugar a la promulgación de la Ley del Suelo de 1998 cuyo artículo 9 señalaba, por vez primera en una legislación española del suelo la obligación de clasificar como suelo "no urbanizable" aquel con riesgo natural acreditado. El problema es que esta norma nunca reglamentó la manera de "acreditar" el riesgo de un espacio geográfico, cuando a nadie escapa que la única forma de determinar este extremo es mediante un análisis de riesgo y su correspondiente cartografía.

Los años finales del siglo XX y los iniciales del presente siglo conocieron la promulgación de leyes y planes de ordenación del territorio en diferentes Comunidades Autónomas, algunos de los cuales fueron elaborados para la reducción del riesgo natural y, específicamente, del riesgo de inundaciones (País Vasco, Andalucía, Cataluña, Comunidad Valenciana, Baleares) (Olcina, 2004). En ellos se aportaba cartografía de riesgo. En otros casos -Madrid- no se aprueban planes territoriales, pero se elabora un documento cartográfico oficial con los mapas de riesgo frente a inundaciones en el territorio de la comunidad autónoma (vid. tabla 3). 
Tabla 3. Cartografías oficiales para la reducción del riesgo de inundaciones mediante ordenación del territorio en España

\begin{tabular}{|c|c|c|}
\hline AMBITo & PROYECTO O PLAN & MAPAS ELABORADOS \\
\hline UNIÓN EUROPEA & $\begin{array}{c}\text { ESPON } \\
\text { (Project 1.3.1.) }\end{array}$ & $\begin{array}{c}\text { MAPAS DE PELIGROSIDAD Y DE RIESGO } \\
1: 30.000 .000\end{array}$ \\
\hline ESTADO & CC.HH & $\begin{array}{l}\text { SISTEMA NACIONAL DE CARTOGRAFIA } \\
\text { DE ZONAS INUNDABLES } \\
\text { (s.t.G. Cartografia mediante LIDAR y Ortofoto) } \\
\text { variable (hasta } 1: 10.000 \text { ) }\end{array}$ \\
\hline $\begin{array}{l}\text { ESTADO - CC.AA- } \\
\text { MUNICIPIOS }\end{array}$ & $\begin{array}{l}\text { PLANES ESPECIALES DE } \\
\text { EMERGENCLA ANTE } \\
\text { NUNDACIONES } \\
\text { (Direstriz Básica de } \\
\text { Inundaciones. 1995) }\end{array}$ & $\begin{array}{c}\text { MAPAS } \\
\text { Escala regional. en las CC.AA ecen plan } \\
\text { homologado. } \\
\text { E1 } \$ 0 \% \text { de los municipios carece de estos planes. }\end{array}$ \\
\hline $\begin{array}{l}\text { PAIS VASCO } \\
\text { (1998) }\end{array}$ & $\begin{array}{l}\text { PLAN TERRITORIAL } \\
\text { SECTORIAL. }\end{array}$ & $\begin{array}{l}\text { MAPAS } \\
1-35.000\end{array}$ \\
\hline $\begin{array}{l}\text { CATALUNA } \\
(2000)\end{array}$ & $\begin{array}{l}\text { PLAN TERRITORIAL } \\
\text { SECTORIAL }\end{array}$ & $\begin{array}{c}\text { MAPAS } \\
1: 10.000 \text { TO } 1: 1.000\end{array}$ \\
\hline $\begin{array}{l}\text { VALENCLA } \\
\text { (2004) }\end{array}$ & $\begin{array}{l}\text { PLAN TERRITORIAL } \\
\text { SECTORIAL }\end{array}$ & $\begin{array}{c}\text { MAPAS } \\
1: 80.000 \\
\text { (actualizado a escala 1:5.000) } \\
\end{array}$ \\
\hline $\begin{array}{l}\text { ANDALUCIA } \\
\text { (desde 1999) }\end{array}$ & $\begin{array}{l}\text { PLAN DE ORDENACIÓN } \\
\text { TERRIORIAL DE ESCALA } \\
\text { REGIONAL } y \\
\text { PLANES SUBREGIONALES } \\
\text { DE ORDENACIÓN }\end{array}$ & $\begin{array}{c}\text { VARIABLE SEGÚN EL AंREA DE TRABAJO } \\
\ldots \\
\text { REGIONAL } \\
1: 400.000 \\
\text { SUBREGIONAL } 1: 50.000 \\
\text { LOCAL } \\
1: 10.000\end{array}$ \\
\hline $\begin{array}{l}\text { MURCLA } \\
\text { (2003) }\end{array}$ & $\begin{array}{l}\text { PLAN TERRITORIAL } \\
\text { GENERAL (FRANIA } \\
\text { LITORAL) }\end{array}$ & $\begin{array}{c}\text { MAPAS } \\
1: 275.000\end{array}$ \\
\hline $\begin{array}{l}\text { MADRID } \\
(2007)\end{array}$ & $\begin{array}{l}\text { CARTOGRAFLA REGIONAL } \\
\text { DE RIESGO DE } \\
\text { INUNDACION }\end{array}$ & $\begin{array}{l}\text { MAPAS } \\
1: 30.000\end{array}$ \\
\hline
\end{tabular}

Elaboración propia

En 2005, el IGME pondría en marcha una interesante iniciativa, el Plan PRIGEO (Plan de Cartografía de Riesgos Geológicos). Sus objetivos serán la creación de una infraestructura cartográfica sobre peligros y riesgos geológicos, el diseño de un sistema de información (SIRGE), la homogenización del tratamiento y explotación de la investigación en esta temática y la contribución a las políticas de divulgación y de educación ambiental. Con este Plan el IGME desarrolla una de las funciones contempladas en su estatuto, como es "estudiar los riesgos por procesos geológicos así como su previsión, prevención y mitigación”. 
Los peligros geológicos a estudiar son: terremotos y tsunamis, volcanismo, avenidas e inundaciones, movimientos del terreno y aludes y, finalmente, peligros ligados a la dinámica litoral. La distribución de la cartografía de peligrosidad de este Plan que se elabora a escala 1:50.000 (salvo en las Islas Canarias, que será a 1:25.000), abarca, en principio, dos tercios del territorio nacional. Además, se contempla la elaboración de mapas de detalle a escala 1:10.000 de algunos núcleos de población y sectores con desarrollo socioeconómico en situación de alto riesgo. En la actualidad proyecto PRIGEO se encuentra en una fase todavía inicial de desarrollo, pero ya se ha presentado la leyenda general que se incorporará a estos mapas oficiales de peligrosidad de inundaciones (Llorente et. alt., 2006).

El año 2006 va a resultar determinante para el impulso de la cartografía de inundaciones en España. Ese año tienen lugar tres acontecimientos que supondrán la consolidación de las cartografías de riesgo de inundación, como elemento importante en los procesos de planificación territorial. El primer lugar, el Observatorio Europeo en red de Ordenación Territorial (ESPON), organismo creado en el marco de la aprobación de la Estrategia Territorial Europea (1999) y de la nueva política territorial europea contemplada en los tratados de Niza y Lisboa, pone en marcha el primer programa de proyectos de investigación para el diagnóstico territorial de la Unión Europea. Se proponen una serie de temas prioritarios de análisis entre los cuales se incluye uno sobre riesgos naturales y tecnológicos en Europa. En este proyecto se da prioridad al análisis de la vulnerabilidad como criterio principal para la determinación del nivel de riesgo de un espacio geográfico. La vulnerabilidad no se mide en función de las victimas ocurridas ni de las potenciales, sino en función de otros aspectos socio-económicos. En efecto, la vulnerabilidad se determina a partir del valor del producto nacional bruto (escala regional), de la densidad demográfica, de la existencia de áreas en el territorio que podrían quedar muy seriamente dañadas si aconteciese un peligro (natural o tecnológico) - es lo que se denomina, "fragmented natural areas" y de la capacidad de respuesta del estado ante un desastre, medida en términos de producto nacional bruto (escala nacional). A partir de ello, se han definido 5 categorías de peligrosidad y otras 5 categorías de vulnerabilidad, de la combinación de las cuales se reconocen 25 niveles de riesgo en el territorio europeo ${ }^{12}$.

Otro hecho destacado en 2006 es el desarrollo del proyecto ARMONIA (Assessing and Mapping multiple Risks for Spatial Planning) en el marco de los proyectos de investigación europeos T6 (Sexto Programa Marco de Investigación y Desarro1lo Tecnológico), que estudiará las cartografías de riesgos naturales en diferentes países europeos, entre ellos España, con objeto de establecer pautas de representación común a la hora de dibujar los mapas de riesgo ${ }^{13}$.

Y ello porque, en tercer lugar, la Comisión Europea estaba estudiando, tras los efectos de las inundaciones ocurridas en Centroeuropa en 2000 y 2005, la posibi-

\footnotetext{
${ }^{12}$ Puede consultarse el contenido integro de este proyecto en la web de ESPON (www.espon.eu)

${ }^{13}$ Los resultados de este proyecto se pueden consultar en http://ec.europa.eu/research/environment/ pdf/publications/fp6/natural_hazards//armonia.pdf
} 
lidad de aprobar una directiva que abordase la cuestión de la peligrosidad natural pero en el marco de la ordenación del territorio. En abril de 2006 se presentaría un primer borrador de la denominada Directiva de Inundaciones. Por vez primera en Europa la ordenación del territorio pasa a ocupar un lugar destacado como método para la reducción del riesgo natural. Esta directiva verá su versión definitiva un año después (DIRECTIVA 2007/60/CE del Parlamento Europeo y del Consejo, de 23 de octubre de 2007 relativa a la evaluación y gestión de los riesgos de inundación $\left.{ }^{14}\right)$. La Directiva establece un marco para la reducción del riesgo para la salud humana, el medio ambiente y la actividad económica asociado a las inundaciones en el territorio de la unión (art. 1). Para ello los Estados miembros realizarán, respecto a cada demarcación hidrográfica o a la parte de una demarcación hidrográfica internacional situada en su territorio, tres documentos:

-Evaluación preliminar del riesgo de inundación (2011)

-Mapas de riesgo de inundación (2013)

-Planes de gestión del riesgo de inundación (2015)

La Directiva obliga a los países europeos a la elaboración de una cartografía detallada de riesgo de inundación que incluirá dos clases de mapas: "mapas de inundaciones" y mapas indicativos de los daños derivados de las inundaciones o "mapas de riesgo de inundación"). Esta cartografía se realizará a escala de demarcación hidrográfica, según la denominación oficial contemplada en la Directiva Marco de Agua 2000/60. Los mapas de inundaciones incluirán las zonas geográficas que podrían inundarse según las hipótesis siguientes:

(a) alta probabilidad de inundación (período de retorno probable de 10 años);

(b) probabilidad media de inundación (período de retorno probable de 100 años);

(c) baja probabilidad de inundación (fenómenos extremos).

Para cada una de estos niveles de probabilidad tendrá que indicarse los niveles del agua previstos, la velocidad de la corriente, cuando proceda y las zonas en las que podría producirse erosión de las orillas y sedimentación de arrastres. Por su parte, los mapas indicativos de daños derivados de inundaciones ("mapas de riesgo de inundación") indicarán los daños potenciales asociados a éstas expresados por medio de los parámetros siguientes:

(a) número de habitantes que pueden verse afectados

(b) daños económicos potenciales en la zona

(c) daños potenciales al medio ambiente.

De manera que la Directiva otorga un papel destacado a la vulnerabilidad social, económica y ambiental a la hora de establecer los niveles de riesgo ante inundacio-

${ }^{14}$ Vid. texto íntegro de esta Directiva en http://www.mma.es/secciones/acm/aguas_continent zonas_asoc/prevencion_inundaciones/pdf/Directiva_Evaluacion_Gestion_Inundaciones.pdf 
nes en un territorio. En España, la elaboración de esta cartografía está coordinada por el Ministerio de Medio Ambiente que ha puesto en marcha el Sistema Nacional de Cartografía de Zonas Inundables para el cumplimiento de lo establecido por la Directiva 60/2007.

En efecto, un decenio después de la elaboración de conclusiones de la Comisión de desastres del Senado y tres de la puesta en marcha del mencionado proyecto Prigeo para el desarrollo de cartografía de riesgos naturales por parte del IGME, en 2008, el Ministerio de Medio Ambiente, en cumplimiento de lo establecido por la Directiva Europea 60/2007 de gestión de inundaciones en el territorio europeo, pone en marcha el Sistema Nacional de Cartografía de Zonas Inundables (SNCZI) que, una vez finalizado, se convertirá en el banco de datos cartográfico oficial sobre inundaciones en España (vid. figura 23).

Figura 23. Tramos fluviales (España Peninsular y Baleares) con estudios de inundaciones incorporadas al SNCZI

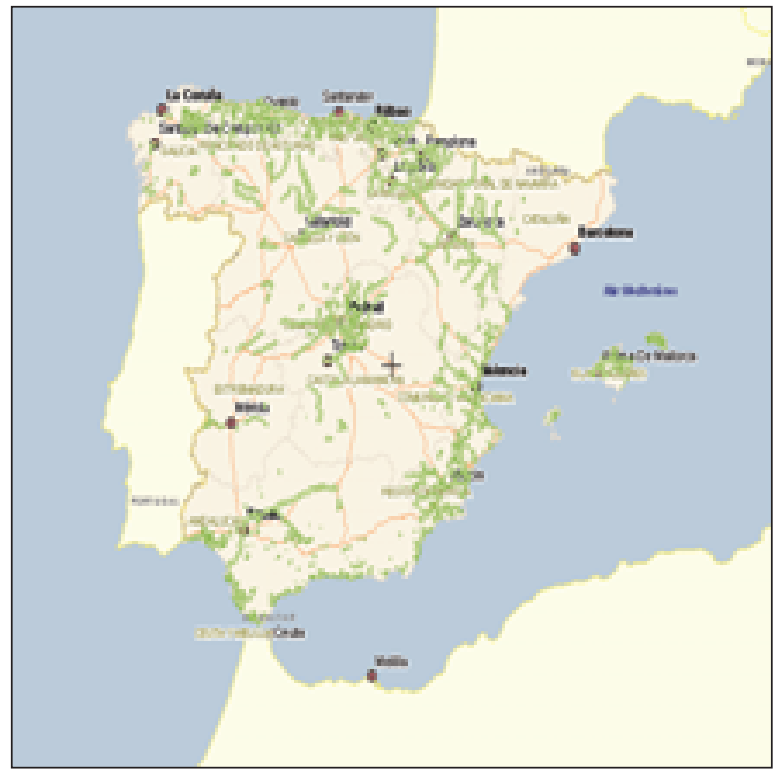

Fuente: MARM

A finales de 2011 las Demarcaciones Hidrográficas han elaborado la Evaluación Preliminar del Riesgo de Inundación en su ámbito territorial de competencia, requisito establecido por la Directiva 60/2007, que ha sido transpuesta al ordenamiento jurídico español por Real Decreto 903/2010, de 9 de julio). La delimitación cartográfica de las "Áreas con riesgo potencial significativo" ha sido volcada al SNCZI. En 2013 tendrá que estar finalizada la cartografía oficial de riesgo de inundación, con los parámetros establecidos en dicha Directiva (vid. figura 24). 
Figura 24. Ejemplo de ficha de localización de áreas con riesgo potencial significativo de inundación

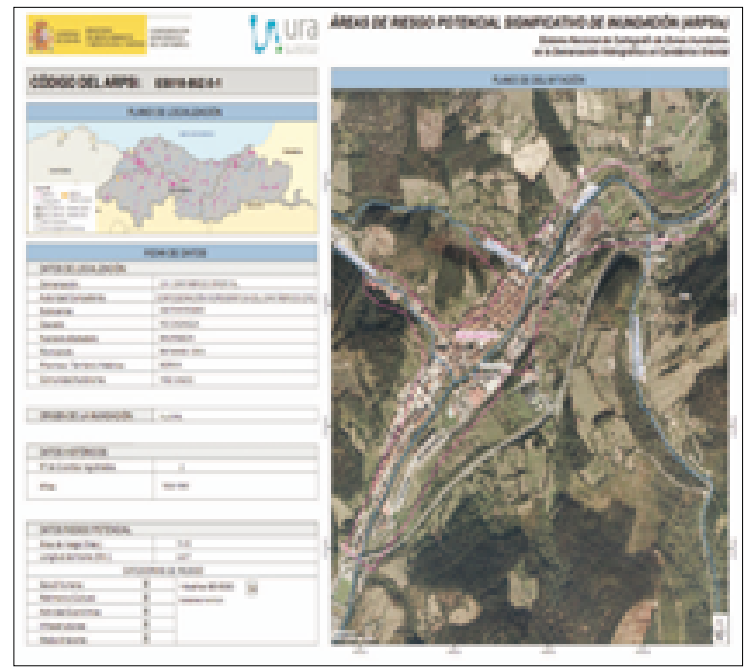

Fuente: Agencia Vasca del Agua

Un último y determinante paso para el desarrollo de cartografías de riesgo natural en España ha supuesto la aprobación de la Ley del Suelo de 2008. En este texto legal se mantiene la obligación de clasificar como "suelo rural" (no urbanizable) aquellos "con riesgos naturales o tecnológicos, incluidos los de inundación o de otros accidentes graves, y cuantos otros prevea la legislación de ordenación territorial o urbanística" (art. 9). Pero ha avanzado un poco más respecto a la mencionada Ley del Suelo de 1998 que nunca explicitó la manera de "acreditar" el riesgo de un territorio. Evidentemente no hay mejor modo de acreditar el riesgo existente en un espacio geográfico que plasmando esta condición en un mapa. Por ello, en la nueva ley del suelo de 2007, a partir de ahora las actuaciones urbanísticas deben ir acompañadas de un informe de sostenibilidad ambiental donde se incluyan, entre otros estudios, un mapa de riesgos naturales del ámbito objeto de ordenación (art. 15). Es la primera vez que una normativa del suelo española obliga a incorporar cartografía de riesgo entre la documentación que debe acompañar los nuevos desarrollos urbanísticos. A falta de reglamento que desarrolle esta ley y que permita aclarar el contenido a incluir estos mapas de riesgo, el Ministerio de Vivienda, en colaboración con el Colegio de Geólogos de España, han editado una Guía metodológica para la elaboración de cartografía de riesgos naturales, de utilidad para el planificador ${ }^{15}$.

${ }^{15}$ Vid. Regueiro y González-Barros, M. (ed.) (2008) Guía Metodológica para la elaboración de cartografías de riesgos naturales en España, Ilustre Colegio Oficial de Geólogos, Ministerio de Vivienda, Madrid, 187 pp. 
En la actualidad, la elaboración de un verdadero mapa de riesgo de inundaciones debe incluir en primer lugar, un análisis de la peligrosidad que integre los parámetros climáticos, hidrológicos, geológicos y geomorfológicos, edáficos y biogeográficos del área a cartografias. A ello debe unirse una cartografía de zonas afectadas elaborada con criterio histórico (documentación) y trabajo de campo que detalle las áreas ocupadas por las aguas con ocasión de episodios destacados. Y por último, un estudio detallado del componente social existente en el área de análisis; esto es, un estudio de la vulnerabilidad, bajo sus diversas manifestaciones (social, económica, cultural, ambiental). Sin lugar a dudas, el gran avance ocurrido en los últimos años en relación con la cartografía de riesgo ha sido la importancia dada al factor de la vulnerabilidad que ha pasado a ocupar un lugar principal en la elaboración de los mapas de riesgo de inundaciones. En otras palabras, no se entiende ya un "mapa de riesgo" sin el análisis de los efectos potenciales sobre la sociedad que ocupa un espacio geográfico, de sus actividades económicas, así como de otros aspectos menos tangibles como la cultura o la calidad ambiental (vid. figura 25).

Figura 25. Representación de diferentes parámetros de vulnerabilidad para el establecimiento de mapas de riesgo de inundación A (riesgo para la salud humana); B (daños económicos en inundaciones históricas)

A
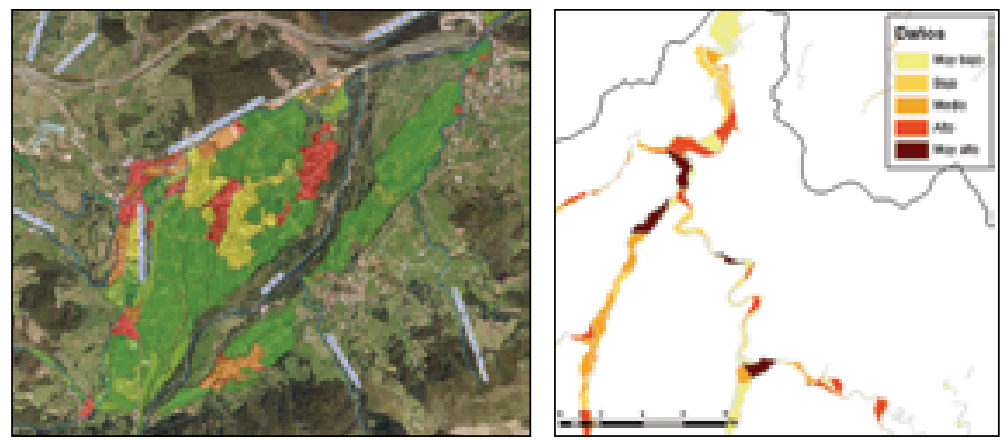

B

Fuente: Evaluación Preliminar del Riesgo de Inundación. Demarcación Hidrográfica del Cantábrico Occidental

Y un último aspecto a destacar es el carácter de documento "nunca cerrado" de los mapas de riesgo, puesto que el territorio es dinámico y regularmente se tienen que poner al día las modificaciones impuestas por los nuevos procesos (demográficos, económicos, ambientales) que van aconteciendo. Uno de ellos va a obligar a hacer una actualización regular de las cartografías de inundaciones: el cambio climático y sus posibles efectos de incentivación de episodios atmosféricos extremos. De manera que el nivel o grado de riesgo de un espacio geográfico podrá verse alterado en las próximas décadas a consecuencia de este proceso ambiental global. Y ello deberá recogerse en los mapas de riesgo, que deben cumplir un principio básico: son herramientas imprescindibles en los procesos de ordenación territorial que se pretendan sostenible y garantes de la vida de las personas que viven en los territorios. 


\section{REFLEXIONES FINALES}

La representación cartográfica de zonas afectadas por inundaciones se inició en España a finales de la Edad Moderna. Y sólo en las últimas décadas del siglo XX se dibujarán mapas de riesgo con localización de áreas potencialmente afectables por una crecida fluvial. Los mapas de riesgo natural son una herramienta esencial en los procesos de planificación territorial. Este carácter ha sido reconocido legalmente en España de forma tardía. De hecho, sólo tras la promulgación de la Ley del Suelo de 2008 (R.D.L. 2/2008) hay exigencia normativa de dibujar mapas de riesgos naturales como elemento de acreditación de la condición de riesgo de un territorio. Y, asimismo, sólo desde la adaptación de la Directiva Europea de gestión de inundaciones (60/2007), llevada a cabo en España en 2010, se han sentado las bases para la creación de un banco de datos oficial sobre cartografía de riesgo de inundación, a modo del existente hace décadas en los Estados Unidos de Norteamérica, gestionado por la Agencia Federal de Gestión de Emergencias (FEMA), que resulta de obligada consulta para la implantación de nuevos usos urbanos en el territorio. La realidad es que en los inicios del segundo decenio del siglo XXI España carece de una cartografía oficial de riesgo de inundación de aplicación válida para todo el territorio; y ello pese a que ésta fue una de las recomendaciones principales de la Comisión Especial de Desastres del Senado Español, creada en 1998, tras el desastre del camping de Biescas.

La Geografía, disciplina que se expresa básicamente con los mapas, es la responsable de elaborar buenas cartografías de riesgo y de plantear mejoras constantes en su elaboración. Retos de futuro como las consecuencias del cambio climático en nuestro ámbito, que puede suponer un incremento de la peligrosidad climática (aumento de extremos atmosféricos) en nuestro territorio, obliga a ello. En esta tarea nos jugamos mucho de nuestra valoración como profesionales útiles y de prestigio ante la sociedad.

\section{BIBLIOGRAFÍA}

AGUILAR CIVERA, I. (2003) El territorio como proyecto. Transporte, obras públicas y ordención territorial en la historia de la Comunidad Valenciana. Consellería de Obras Públicas, Urbanismo y Transportes. Generalitat Valenciana, Valencia, 277 p.

ALBEROLA ROMÁ, A. y OLCINA CANTOS, J. (edits.) (2009) Desastre natural, vida cotidiana y religiosidad popular en la España moderna y contemporánea. Universidad de Alicante, Alicante, $470 \mathrm{pp}$.

AYALA-CARCEDO, F.J. (1986). Mapa previsor de riesgos por inundaciones en núcleos urbanos de Andalucía y Extremadura. Instituto Geológico y Minero de España. Madrid.

AYALA-CARCEDO, F. J. (2000): “La ordenación del territorio en la prevención de catástrofes naturales y tecnológicas. Bases para un procedimiento técnico-administrativo de evaluación de riesgos para la población", en Boletín de la Asociación 
de Geógrafos Españoles, no 30 (monográfico sobre "Riesgos Naturales"), Madrid, Asociación de Geógrafos Españoles, pp. 37-49.

AYALA-CARCEDO, F. J. (2002): "El sofisma de la imprevisibilidad de las inundaciones y la responsabilidad social de los expertos. Un análisis del caso español y sus alternativas", en Boletín de la Asociación de Geógrafos Españoles, $\mathrm{n}^{\circ}$ 33, Madrid, Asociación de Geógrafos Españoles, pp. 79-92.

AYALA-CARCEDO, F. J. y OLCINA CANTOS, J. (coords.) (2002): Riesgos Naturales. Editorial Ariel. Col. Ciencia, Barcelona, 1512 p.

BECK, U. (2002): La sociedad del riego global. Madrid, Edit. Siglo XXI.

BOIX, V. (1865) Memoria histórica de la inundación de la Ribera de Valencia en los días 4 y 5 de noviembre de 1864. (ed. facsimil). Imprenta Graficuatre. Alzira, 1986, 264 pp.

BOSCH JULIA, M (1866) Memoria sobre la inundación del Júcar en 1864. Imprenta Nacional, Madrid, (ed. facsimil, libreria Paris Valencia, Valencia), 425 p.

BOSQUE SENDRA, J. et alt. (1999). «Sistemas de Información Geográfica y cartografía de riesgos tecnológicos. El caso de las instalaciones para la gestión de residuos en Madrid». En Industria y Medio Ambiente, Actas de las VIII Jornadas de Geografia Industrial. Alicante, 27-29 de octubre de 1999.

CALVO GARCÍA-TORNEL, F. (2001). Sociedades y territorios en riesgo. Ediciones del Serbal, Barcelona, $86 \mathrm{p}$.

CLARK, G. et alt. (1998). «Assessing the vulnerability of coastal communities to extreme storms: the case of Revere, MA., USA». Mitigation and Adaptation Strategies for Global Change, 3, p. 59-82.

DAUPHINÉ, A. (2003): Risques et catastrophes. Observer, spatialiser, comprendre, gérer. París, Armand Colin.

DEL MORAL ITUARTE, L. (1991) La obra hidráulica de la cuenca baja del Guadalquivir (siglos XVII-XX). Gestión del agua y organización del territorio. Universidad de Sevilla. Consejería de Obras Públicas y Transportes. Junta de Andalucía y Ministerio de Agricultura, Pesca y Alimentación, Sevilla, 591 pp.

DÍEZ HERRERO, A. (1999). «Utilización de los SIGs en el análisis del riesgo de inundación en el Alto Alberche (cuenca del Tajo)». En LAÍN HUERTA, L. (ed.). Los Sistemas de Información Geográfica en los riesgos naturales y el medio ambiente. Instituto Geológico y Minero de España, Ministerio de Medio Ambiente, Madrid, p. 49-68.

DÍEZ HERRERO, A. (2002). «Aplicaciones de los Sistemas de Información Geográfica al análisis del riesgo de inundaciones fluviales». En LAÍN HUERTA, L. (ed.). Los Sistemas de Información Geográfica en la gestión de los riesgos geológicos $y$ en el medio ambiente. Instituto Geológico y Minero de España, Ministerio de Medio Ambiente, Madrid, p. 87-112. 
DÍEZ HERRERO, A. y PUJADAS FERRER, J. (2002). «Los mapas de riesgos de inundaciones». En AYALA-CARCEDO, F.J. y OLCINA CANTOS, J. (coords.). Riesgos naturales. Ariel Ciencia, Barcelona, p. 997-1012.

DÍEZ HERRERO, A.; LAIN-HUERTA, L. y LLORENTE-ISIDRO, M. (2008). Mapas de peligrosidad por avenidas e inundaciones. Guía metodológica para su elaboración. Publicaciones del Instituto Geológico y Minero de España. Serie Riesgos Geológicos/Geotécnica no 1, 190' págs., Madrid.

EEA - European Environmental Agency - (2003): Mapping the impacts of recent natural disasters and technological accidents in Europe. (Copenhagen, European Environmental Agency; Environmental issue report No. 35), 48 pp.

ENCICLOPAEDIA BRITANICA (1771) Dictionary of Arts and Sciences, Edinburgh. 3 vols.

ESTRELA MONREAL, T. (1999). «Modelo Gisplana: aplicación de un SIG al análisis de inundaciones en planas costeras». En LAÍ́N HUERTA, L. (ed.). Los Sistemas de Información Geográfica en los riesgos naturales y el medio ambiente. Instituto Geológico GeoMinero de España, Ministerio de Medio Ambiente, Madrid, p. 35-46.

ESTRELA, Ma.J., (ed.) (2008): Riesgos Climáticos y Cambio Global en el Mediterráneo Español. ¿Hacia un clima de extremos?, Fundación Centro de Estudios Ambientales del Mediterráneo. Colección Interciencias, Valencia, 291 pp.

EXCIMAP (2007): Handbook on good Practices for flood mapping in Europe, European Commision, 57 pp. (available on http://ec.europa.eu/environment/water/ flood_risk/flood_atlas/pdf/handbook_goodpractice.pdf).

FLEISCHHAUER, M., GREIVING, S., \& WANCZURA, S. (eds) (2006): Natural Hazards and Spatial Planning in Europe, Versandbuchhandlung \& Verlag Dorothea Rohn, Dortmund, $204 \mathrm{pp}$.

FRANCÉS GARCÍA, F. et alt. (2000). «Un ejemplo de análisis regional del riesgo de inundación en el marco de la planificación territorial». Serie Geográfica, 9, Universidad de Alcalá de Henares, p. 237-248.

FREIXES, A. (1998). «Cartografies hidrològiques i Sistemes d'Informació Geogràfica en la gestió dels recursos hídrics». Espais. Monogràfic, 44, p. 78-84.

GARCÍA RUIZ, J. Ma . (2000). «La catástrofe de Biescas y la predicción de riesgos hidromorfológicos». Ponencia en las Primeres Jornades Sobre Risc i Territori. Barcelona, 30 y 31 de mayo.

GIL OLCINA, A. (dir.) (2004) La cultura del agua en la Cuenca del Segura. Fundación CajaMurcia, Murcia, 604 pp.

GIMÉNEZ FONT, P. (2008) Las transformaciones del paisaje valenciano en el siglo XVIII. Una perspectiva geográfica. Institució Alfons el Magnànim, Diputació de València, Valencia, $456 \mathrm{pp}$. 
GIMENEZ FONT, P. (2009) "Cartografía histórica y alteración de cursos fluviales en la España mediterránea”, en ALBEROLA, A. y OLCINA, J. (edits.) (2009) Desastre natural, vida cotidiana y religiosidad popular en la España moderna y contemporánea. Universidad de Alicante, Alicante, pp. 391-432.

GONZALEZ TASCON, I. (coord.) Felipe II. Los ingenios y las máquinas. Ingeniería y obras públcias en la época de Felipe II. Sociedad Estatal para la Conmemoración de los Centenarios de Felipe II y Carlos V, 1998. Madrid, 490 pp.

GREIVING, S., FLEISCHHAUER, M. \& LÜCKENKÖTTER, J. (2006): A Methodology for an Integrated Risk Assessment of Spatially Relevant Hazards. In: Journal of Environmental Planning and Management, Vol. 49, No. 1 (January), pp. 1-19.

GREIVING, S., FLEISCHHAUER, M. \& WANCZURA, S. (2007): "Planificación territorial para la gestión de riesgos en Europa", Boletín de la Asociación de Geógrafos Españoles, $\mathrm{n}^{\circ}$ 45, Madrid, pp. 49-78.

HILPERT, K., MANNKE, F and SCHMIDT-THOMÉ, P. (2007): Towards climate change adaptation strategies in the Baltic Sea Region, GTK, Finland, Baltic Sea Region (Interreg III B).Espoo, 55 p.

IPCC (2007): Climate Change 2007. Impacts, adaptation and vulnerability. (Working Group II Report). United Nations Environment Programme.(disponinle en http://www.ipcc.ch/ipccreports/assessments-reports.htm).

LAZUÉN ALCÓN, J. A. (2000). «El funcionamiento de las Administraciones Públicas en la Gestión del Riesgo ligado al Territorio. La situación en España». Ponencia en las Primeres Jornades Sobre Risc i Territori. Barcelona, 30 y 31 de mayo de 2000 .

LLORENTE, M.; DIEZ, A. y LAIN, L. (2006) "La experiencia del IGME en cartografía de peligrosidad de avenidas torrenciales e inundaciones: de Casiano Prado a PRIGEO", en DÍEZ HERRERO, A; LAÍN HUERTA, L y LLORENTE ISIDRO, M. (edits.) Mapas de peligrosidad de avenidas e inundaciones. Métodos, experiencias y aplicación, IGME, Madrid, pp. 41-63.

MARTIN, P. (1998). Ces risques que l'on dit naturels. Èdisud, Aix-en-Provence, p. 111-121, 134-141 y 183-186.

MARTINEZ CARRILLO, Ma LL. (2004) "Las avenidas del río Segura en la Baja Edad Media. Apuntes cronológicos". Revista ArqueoMurcia n 2, CARM. Consejería de Educación y Cultura. Dirección General de Cultura. Servicio de Patrimonio Histórico , Murcia, pp. 1-35.

MATA OLMO, R. y OLCINA CANTOS, J. (2010) "El sistema de espacios libres" en Teoría y Práctica para una ordenación racional del territorio (Luis Galiana y Julio Vinuesa, coords). Ed. Síntesis, Madrid, pp.87-127.

MONMONIER, M. (1997). Cartographies of danger. Mapping Hazards in America. The University of Chicago Press, Chicago, p. 1-14, 105-126, 216-238 y 286-295. 
OLCINA CANTOS, J. (2007) Riesgo de inundaciones y ordenación del territorio en España. Instituto Euromediterráneo del Agua, Murcia

OLCINA CANTOS, J. (2010) "Cambio climático y riesgos climáticos en España", Investigaciones Geográficas, 49. Instituto Universitario de Geografía. Universidad de Alicante, pp. 197-220.

OLLERO, A. y UREÑA, J.M. (2000) "Criterios y propuestas para la ordenación de áreas fluviales". Ciudad y territorio. Estudios territoriales, 126, pp. 689-710

ONU (2004): Living with Risk: A Global Review of Disaster Reduction Initiatives, Nairobi, ISDR.

PAULSSON, B. (1992). Urban Applications of Satellite Remote Sensing and GIS analysis. The World Bank, Washington, p. 23 y 24.

RIBAS PALOM, A. (1994). Natura, societat i calamitat. Una aproximació a les inundacions històriques de la ciutat de Girona. Tesis doctoral. Girona. Universitat de Girona, p. 1, 2, 9-65 y 361.

RIBAS, A. y ROSET, D. (1997). «La previsió i gestió de les emergències». En SAURÍ, David (coord.). Les inundacions. Diputació de Barcelona, Barcelona, p. 89105.

RIBAS, A. y SAURI, D. (2006): "De la geografía de los riesgos a las geografías de la vulnerabilidad", en NOGUE, J. y ROMERO, J., eds. (2006) Las otras Geografias. Ed. Tirant Lo Blanch. Col. Crónica. Valencia, pp. 285-299.

SAURÍ, D. (1997). «Introducció». En SAURÍ, David (coord.). Les inundacions. Diputació de Barcelona, Barcelona, p. 7-11

SAURÍ, D. (2003): “Tendencias recientes en el análisis geográfico de los riesgos ambientales", Areas. Revista de Ciencias Sociales. (Universidad de Murcia), 23, pp. 8-30.

SAURÍ, D. y RIBAS, A. (1994): "El análisis del riesgo de avenida en las escuelas geográficas anglosajona, francesa y española”, Estudios Geográficos, 216, pp. 481-502.

SCHMIDT-THOMÉ, P. (edit.) (2005): ESPON Project 1.3.1 - The spatial effects and management of natural and technological hazards in general and in relation to climate change (Draft Final Report, Espoo, Geological Survey of Finland), $193 \mathrm{pp}$.

SCHMIDT-THOMÉ, P. (edit) (2006): Natural and technological hazards and risks affecting the spatial development of European regions. Geological Survey of Finland, Special Paper 42, Espoo, 167 pp.

SUÁREZ L. y REGUEIRO, M. (Eds). (1997) Guía Ciudadana de los Riesgos Geológicos. Ilustre Colegio Oficial de Geólogos, 196 pp. 
VILLEVIEILLE, A. (coord.) (1997) : Les risques naturels en Méditerranée. Situation et perspectives. Les Fascicules du Plan Bleu. Paris, 160 p.

VV.AA. (1960) Las inundaciones de Valencia en 1957. Historia de la riada y perspectiva de la ciudad. Revista Propiedad y Construcción, $\mathrm{n}^{\mathrm{o}} 21$ y 22 extraordinario. Valencia, $293 \mathrm{pp}$.

VV.AA. (2006): Cambios de ocupación del suelo en España. Implicaciones para la sostenibilidad. Observatorio de la Sostenibilidad e España, Ministerio de Medio Ambiente. Alcalá de Henares, 485 p. 